\title{
A Biased Load Manager Home Energy Management System for Low-cost Residential Building Low-income Occupants
}

\author{
${ }^{1,2,6}$ Chukwuka G. Monyei, ${ }^{1}$ Aderemi O. Adewumi, ${ }^{3}$ Daniel Akinyele, ${ }^{4}$ Olubayo M. \\ Babatunde, ${ }^{2}$ Michael O. Obolo and ${ }^{5}$ Joshua C. Onunwor \\ ${ }^{1}$ Applied Artificial Intelligence Research Unit, School of Mathematics, Statistics and \\ Computer Science, University of KwaZulu-Natal, Westville Campus, Private Bag X54001, \\ Durban 4000, South Africa \\ ${ }^{2}$ Gidia Oaks Centre for Energy Research, Lagos, Nigeria \\ ${ }^{3}$ Elizade University, Ilara-Mokin, Ondo State, Nigeria \\ ${ }^{4}$ Department of Electrical and Electronics Engineering, University of Lagos, Nigeria \\ ${ }^{5}$ Department of Electrical and Electronics Engineering, Covenant University, Ota, Ogun \\ State, Nigeria \\ ${ }^{6}$ Corresponding author \\ chiejinamonyei@gmail.com, adewumia@ukzn.ac.za, \\ daniel.akinyele@elizadeuniversity.edu.ng, olubayobabatunde@gmail.com, \\ michaeldammy@ymail.com, joshuaonunwor@yahoo.com
}

\begin{abstract}
This research paper presents the development of a biased load manager home energy management system for low-cost residential building occupants. As a smart grid framework, the proposed load manager coordinates the operation of the inverter system of a low cost residential apartment consisting of rooftop solar photovoltaic panels, converter and battery, and provides a platform for discriminating residential loads into on-grid and off-grid supply classes while maximizing solar irradiance for optimum battery charging and improving consumer comfort from base levels. Modelled in a Matlab simulation environment, the system incorporates a converter system for maximum power point tracking using a hopping algorithm, with a dedicated mechanism for smart dispatch of specified loads to meet the users' comfort based on the priority ranking of the loads. Results obtained indicate a 34\% reduction in electricity cost, $26 \%$ reduction in carbon emissions and a $4 \%$ increase in comfort level for the photovoltaic/battery/utility option compared to the utility only option. The results further show that cost is a major factor affecting the users' comfort and not necessarily dispatch of appliances to meet energy needs. The research can be useful for encouraging the adoption of the photovoltaic/battery/utility option by low/middle income energy users in developing countries.
\end{abstract}

Keywords: - low-cost residential buildings, BLM-HEMS, hopping algorithm, consumer comfort, return on investment, carbon footprint

\section{Highlights}

- Presents a load manager for low-income residential homes.

- Evaluates the contribution of the load manager in improving household comfort.

- Evaluates associated reduction in carbon emissions and electricity cost.

- Discusses and presents solution to the challenge of adopting the load manager.

\subsection{Introduction}

Energy (electricity) access is still a major problem for over 800 million people in subSahara Africa (SSA) and South Asia. In Nigeria, over 80 million people are still without 
access to grid electricity. Various reasons have been attributed to the inability to extend the grid and increase electricity access; cost of grid expansion, ageing transmission networks, mounting debts and poor generation. In arguing on the need for increase in electricity access, its impact on the socio-economic life of consumers has been highlighted with energy (electricity) poverty linked to actual poverty. Electricity access has also been opined to be a major factor that determines the level of success of the millennium development goals (MDGs) [1]. The sustainable development goals (SDGs) as a successor to the MDGs has goals 7 and 11 aimed at ensuring affordable and clean energy and building sustainable cities and communities. In achieving goals 7, electricity access to affordable and clean energy is being targeted to reduce emissions and make cities safe and sustainable (goal 11) by 2030 [2].

Solar home systems (SHSs) have been a much-researched alternative proposed for offgrid and on-grid homes. In Brazil for example, a study on the economic and technical advantage of domestic solar hot water systems (DSHWS) was conducted in [3] where it was discovered that annual savings on electricity bills was about 38\%. Similarly, [4] conducted a survey across Uganda and Kenya where it was discovered that the adoption of solar PV systems has led to reduced usage of kerosene (for lighting) and reduction in phone charging outside of homes. In a review work by [5], the utilization of solar thermal collectors vary across regions with major uses including district heating, process heating, swimming pool heating etc. As a scalable alternative, homes could purchase configurations of photovoltaic (PV) panels, batteries, converters and inverters that meet their specifications (cost, capacity, number of supply days without sunshine etc.). Studies have also been conducted on the integration of SHSs with the conventional grid for offsetting peak loads leading to feed-intariffs (FiTs) systems that compensate consumers for electricity sold to the grid [6]. In managing these SHSs, various home energy management systems (HEMs) have also been proposed. While the incorporation of SHSs in developed economies (Europe, North America, Australia, Singapore, Japan) is mainly to improve the penetration of renewable energy and robustness of the electricity grid in the developed economies, it serves a different purpose in Nigeria. Due to the peculiarity of electricity supply in Nigeria (frequent blackouts and grid collapse, low grid coverage network, ageing generation, transmission and distribution network, low number of metered households etc.), SHSs is often deployed as an alternative to grid supply.

Based on the study in [7], about $69 \%$ of Nigerians are poor (using the baseline of 55000 Naira, $\$ 180.33$ yearly income). Table 1 presents the absolute poverty measure for 2003/2004 and 2009/2010 across Nigerian states cutting across the geo-political zones in Nigeria. The baseline yearly earning used in 2003/2004 was about 29000 Naira (\$95.08). The breakdown of the average monthly expenditure of households in the different geo-political zones within Nigeria on gas, electricity, petrol and diesel is presented in Table 2 [8] while Table 3 presents a summary on the frequency of electricity blackouts across the geo-political zones in Nigeria [9].

Across the states of interest, expenditure on electricity monthly constitutes $4.42 \%$ (Abia), $2.03 \%$ (Borno), $4.7 \%$ (Edo), 2.78\% (Katsina), 2.76\% (Kogi) and 5.9\% (Lagos) of the total monthly expenditure of households. The percentage values however must not be used in ranking states. This is because, in actual monetary terms, purchasing power and actual expenditure of households vary across the geo-political zones. For example, while households in Lagos spent 13105 Naira (\$43) monthly on electricity, it was 9972 Naira (\$33) in Abia, 8152 Naira (\$27) in Edo, 5401 Naira (\$18) in Kogi, 2216 Naira (\$7) in Borno and 
2667 Naira (\$9) in Katsina. In the use of alternative electricity sources, Lagos state (considering our states of interest) has over $26 \%$ of its households having generator as an alternative [10] with only $68 \%$ of its households using the grid as their only source of electricity. Solar PV penetration for Lagos according to [10] is put at $0.2 \%$ of its population. The consequence of the high penetration of petrol and diesel generators within Lagos is high carbon footprint since it has been generally established that the residential and building sector accounts for over $40 \%$ of global energy consumption [11].

The advent of SHSs has inadvertently increased discussions and research on HEMs due to the increasing need to match supply with demand. Owing to the variability and stochastic nature of weather elements, HEMs have proven to be a viable platform for ensuring that SHSs are well utilized to guarantee consumer comfort and satisfaction. An energy flow management algorithm was presented in [11] for a grid-connected PV system that incorporated battery storage while [12] designed and tested a HEMs integrating a learning prediction algorithm that was based on neural-network for forecasting power production of a house's solar PV plant and its power consumption across a time span. The effect of sending feedback on previous energy consumption to households was also evaluated by comparing consumption drop/increase across a time frame in [13] where a 3.4\% drop in energy (electricity) consumption was observed. Data error impact on HEMs was studied in [14] while [15] presented a conceptual distributed integrated energy management (diEM) system for residential buildings. The aim of [15] is to minimize operational energy cost for households through load shifting to maximize renewable energy power produced. A life cycle assessment was conducted by [16] where the environmental impact of HEMs in terms of their potential benefits and detrimental impacts was evaluated. A negative energy payback time was computed for home automation devices due to the energy consumption of smart plugs. Foresee $^{\mathrm{TM}}$ was presented by [17] as a user-centred HEMs for optimizing its operations to achieve efficiency and utility cost savings. Abushnaf et al. in [18] made extensive arguments on the ability of HEMs to optimize residential building energy use especially in tackling the problems of green-house gas emission and energy wastage. Further reading on HEMs can be found in [19].

The objectives of HEMs vary. For example, in [20], a project is presented to increase the monetary value of photovoltaic (PV) solar production for residential application with the aims of reducing the cost of electricity and improving the local utilisation of solar PV. Also, in [21], game theory was used in formulating an energy consumption scheduling game to minimise energy costs and reduce the peak-to-average ratio of the total energy demand. Similarly, in [22], the objective of HEMs was improved well-being/comfort while [23] describes the development of a control system for demand-side management in the residential sector with the incorporation of embedded generation. The utilization of car battery discharging in achieving peak shaving was studied in [24] with up to $64 \%$ reduction in peak demand achieved. In [25], the problem of optimally scheduling a set of appliances at the end user premises for a reduction in electricity cost while taking into consideration such factors as comfort and timeliness was solved, while reduced cost and optimized consumption pattern were the objectives of HEMs in [26]. Also, HEMs sought to optimize consumption and improve well-being in [27], while reduced cost, emissions and optimized consumption were the objectives of HEMs in [28]. Furthermore, various scheduling approaches have been reported in literature. For example in [29], simple linear programming was used for an optimisation model in adjusting the hourly load level for a given consumer in response to hourly electricity price. The aim was to maximize the utility derived by the consumer subject 
to a minimum daily energy consumption level. Also, simple linear programming was also applied in [30] to achieve a trade-off between minimizing the electricity payment and minimizing the waiting time for the operation of each appliance in a household under real time pricing. A modified and mild intrusive genetic algorithm (MMIGA) was applied in [31] for the optimal allocation of load in an off-grid household while MMIGA was applied in [32] for optimally scheduling appliances for a grid connected house considering the user preference. In [33], a constrained multi-objective optimisation problem (CMOP) is formulated and solved using evolutionary algorithms (EAs).

The localization of HEMs in Nigeria has been extensively researched in literature. In [31], the authors designed a load manager for optimizing the dispatch available solar PV power among competing loads for an off-grid house. While the proposed load manager aimed at optimizing available power, issues such as comfort and relevance of dispatched goods to overall user satisfaction were not considered. An improvement was provided in [32] where the authors developed an interface for on-grid homes in managing their electricity consumption with the influence of grid interruption and for varying daily budget. While comfort result was not evaluated in [32], user satisfaction was evaluated in [34] and used in dispatching loads. The concept of scalable SHSs for various households was also considered in [35] with various hybrid configuration of electricity sources evaluated for cost, emissions and energy dumping in [36]. A load manager utilizing mixed integer linear programming for improving the comfort level of households utilizing PV/battery under intermittent solar power was proposed in [37] while a rule based load management scheme for a stand-alone PV/battery system in a residential building was developed in [38].

A critical observation of the literature on HEMs application and management in Nigeria shows that none has been able to present a comprehensive management system for low/middle income homes, especially in addressing the issue of PV/battery sizing based on the financial level of the household and synergizing the PV/battery system operation with the grid to dispatch specific loads at specific times. Furthermore, none of the researched literature on HEMs management in Nigeria has presented a complete report on the potential payback period carbon footprint reduction (when compared with other alternatives) and energy cost/kWh utilizing PV/battery/utility for a low/middle income household.

This work thus models and investigates the PV/battery/utility option for a low-cost residential house that incorporates the BLM-HEMS for smart load dispatch, battery management and intelligent converter control, and compares its associated statistics such as electricity cost reduction, comfort/satisfaction level improvement, carbon footprint reduction and return on investment (RoI) with the Utility only option and Utility/generator option (without BLM-HEMS). In doing this, this work advocates for the adoption of the $\mathrm{PV} /$ battery/utility option as a viable alternative to mitigate grid interruption and improve the satisfaction level of low/middle income households with cost constraints.

In this paper, we acknowledge that the adoption and utilization of HEMs faces critical challenges in Nigeria due to the rising cost of electricity and frequent blackouts in the country. However, the high prevalence of poverty and low purchasing power of Nigerian households mean that most PV/battery systems are usually undersized for load and number of days without sunshine. The demerit of such sizing means that conventional HEMs fail to meet user expectations in terms of load management, comfort/satisfaction level, cost reduction, reduction in carbon footprint etc. Also, most HEMs are for off-grid homes or 
application. The disadvantage of off-grid applications means that the advantage of lower electricity cost from the utility (when available) cannot be leveraged during insufficient PV/battery capacity.

This paper presents BLM-HEMS which offers households with grid supply the opportunity of leveraging the advantage of low electricity cost from the utility in dispatching their loads along with the PV/battery. This configuration - PV/battery/utility being advocated in this paper incorporates BLM-HEMS in MPPT tracking, efficient battery management and smart load dispatch to improve household comfort, reduce electricity cost and carbon footprint and guarantee the repayment of the initial purchase and installation costs within 25 years of operation based on the evaluated yearly savings. The proposed solution aims at tackling the problem of low comfort/satisfaction level often encountered from households with undersized PV/battery systems with utility (grid) availability.

The rest of the paper is organized as follows; Section 2.0 presents the methods including modelling of the PV panels, converter design, battery management and load dispatch while the results and discussions including sensitivity analysis and policy recommendations are presented in Section 3.0. The paper is concluded in Section 4.0.

\subsection{Methods}

In justifying the proposed methods, we first justify its need by evaluating a comfort expenditure plot (figure 1) for both the use of the utility and the generator (independently) in meeting the needs of a household.

Table 4 presents the daily utilization profile of loads (LP1 - LP6). The computation of the monthly cost of dispatching loads (LP1 - LP6) assuming uninterrupted power supply is shown in equations (1) - (3). As seen from equations (1) - (3), about $\$ 14.43$ representing about $33.5 \%$ of the average monthly expenditure on electricity is expended in dispatching LP1 - LP6 (if grid is assumed available throughout) monthly.

Compensating for poor power supply and frequent grid interruptions, a fraction of $C_{M}^{\cos t}$ (moderated monthly electricity cost) is usually expended. Table 5 presents the Needs Appliances Matrix for a low-cost house under consideration. The loads (appliances) under consideration (LP1 - LP6) are classified based on their ability to dispatch the need class (lighting, cooling, entertainment and others) being considered. For example, LP2 (indoor lighting) and LP3 (outdoor lighting) are the only appliances (loads) that can dispatch the lighting (indoor and/or outdoor) need of the house at any time. The associated costs of unmet hourly load due to power outage and the hourly cost of dispatching loads LP1 - LP6 using the Utility only options are presented in Table 6. Equation (4) provides the computation of the associated utility-based comfort level of the household under consideration. The next best alternative to a middle-class home electrification is the petrol generator. Table 7 presents some basic facts associated with a typical $6.5 \mathrm{kVA}$ petrol generator which is predominant among homes surveyed around the low-cost housing estate.

Assuming full dispatch always for LP5 and LP6, then $@=1$ and $\&=1$. For hours $1-7$ and $17-24$ during weekdays and weekends and $d f=0.85$, total daily consumption $\left(T_{D C}\right)$ without $d f$ moderation amounts to $8087 \mathrm{Wh}$.

By incorporating $d f$, 
$T_{D C}^{M}=T_{D C} \times d f$

This implies that $T_{D C}^{M}=8087 \times 0.85=6873.95 \mathrm{Wh} /$ day

Assuming 30 days/month,

$M C=T_{D C}^{M} \times 30=6873.95 \times 30=206218.50 W h$

Converting to $\mathrm{kWh}$ results in $M C=206.22 \mathrm{kWh}$

$E_{P C}=\$ 0.07 / \mathrm{kWh}$

This implies that $C_{M}^{\text {cost }}$ is evaluated as;

$C_{M}^{\text {cost }}=M C(k W h) \times E_{P C}$

$C_{M}^{\cos t}=206.22 \times 0.07=\$ 14.40$

Where, $T_{D C}^{M}$ is the demand factor moderated total daily consumption (Wh or kWh), $M C$ is the monthly electricity consumption (Wh or $\mathrm{kWh}), E_{P C}$ is the electricity cost per unit $(\$ / \mathrm{kWh})$ and $C_{M}^{\cos t}$ is the monthly cost of $T_{D C}^{M}(\$) . j$ is the index of the needs-set $J$ such that $J=\{N-1, N-2, N-3, N-4\}, H_{i, j}$ is the hour $i$ demand for need $j, C_{i, j}^{\text {utility }}$ is the utility cost of dispatching need $j$ for hour $i$ and $C_{i, j}^{\text {Total-unmet }}$ is the baseline comfort cost of need $j$ for hour $i$. The comfort level for dispatching need $j$ in hour $i$ using the utility is $U_{i, j}^{u t i l y}$. It must be pointed out that the $C_{i, j}^{\text {unmet }}$ values for computation shown in Tables 6 and 8 assume full dispatch of all appliances related to the needs $(\mathrm{N}-1, \mathrm{~N}-2, \mathrm{~N}-3$ and $\mathrm{N}-4)$ and is $C_{i, j}^{\text {Total-unmet }}$.

In the results, the actual values for $C_{i, j}^{u n m e t}$ would be computed based on the appliances selected by the user and eventually dispatched for the hour under consideration. While it is expected that the computation of $C_{i, j}^{\text {unmet }}$ would directly sum the associated comfort costs for unmet loads intended to be dispatched, $C_{i, j}^{\text {unmet }}$ sums up the comfort cost of dispatched loads. The reason for this is because the baseline comfort of the household is assumed based on all the loads associated with a need being dispatched. Thus, equations (4a) and (4b) aim at penalizing the differential established by $C_{i, j}^{\text {Total-unmet }}-C_{i, j}^{\text {unmet }}$.

The computation of $U_{i, j}^{u t i t y}$ in the case of full dispatch is as follows:

Given baseline comfort level $U_{\text {baseline }}$ to be 5 , then

$U_{i, j}^{\text {utility }}=U_{\text {baseline }}-\frac{C_{i, j}^{\text {utility }}-C_{i, j}^{\text {unmet }}}{C_{i, j}^{\text {unmet }}}$

However, when all the appliances scheduled for dispatch in an hour to meet any need are not all dispatched eventually due to PV/battery for instance being insufficient, then equation (4a) is modified to become equation (4b) as:

$U_{i, j}^{m t d}=U_{\text {baseline }}-\frac{C_{i, j}^{\text {mtd }}-C_{i, j}^{\text {unmet }}}{C_{i, j}^{\text {Total-unmet }}}$

Such that $C_{i, j}^{\text {unmet }} \leq C_{i, j}^{\text {Total-unmet }}$ and for fixed $C_{i, j}^{\text {mtd }}$, as $C_{i, j}^{\text {unmet }} \rightarrow C_{i, j}^{\text {Total-unmet }}, U_{i, j}^{\text {mtd }}$ increases, where $m t d=\{$ utility, $P V /$ battery/utility, utility/generator $\}, C_{i, j}^{\text {unmet }}$ is the sum of the comfort 
cost of the loads dispatched for the hour and that were intended to be dispatched, $C_{i, j}^{m t d}$ is the hourly cost of dispatching electricity for any $m t d$ while $C_{i, j}^{\text {Total-unmet }}$ is the cumulative/baseline comfort cost for any need ( $\$ 0.13$ for $\mathrm{N}-1, \$ 0.05$ for $\mathrm{N}-2, \$ 0.02$ for $\mathrm{N}-3$ and $\$ 0.05$ for $\mathrm{N}-4$ ). Table 9 presents the comfort based cost for each appliance which is used in computing $C_{i, j}^{\text {unmet }}$. It is observed from Table 9 that $\mathrm{N}-1$ need has the highest $C_{i, j}^{\text {Total-unmet }}$ of $\$ 0.13$ followed by $\mathrm{N}-2(\$ 0.05)$ and $\mathrm{N}-4(\$ 0.05)$ with $\mathrm{N}-3$ having the lowest at $\$ 0.02$. The build-up of $C_{i, j}^{\text {Total-unmet }}$ for N-1, N-2 and N-4 is based on their sub-units (LP2(1) - LP2(6), LP3(1) LP3(2), LP4(1) - LP4(3), LP5(1) - LP5(3) and LP6(1) - LP6(2)). We can thus infer based on $C_{i, j}^{\text {Total-unmet }}$ for the various needs $(\mathrm{N}-1, \mathrm{~N}-2, \mathrm{~N}-3, \mathrm{~N}-4)$ that lighting takes the most priority, followed by cooling, others and entertainment. Expanding on equations (4a) and (4b), 3 scenarios are likely to occur:

- Scenario 1: $U_{i, j}^{m t d}<U_{\text {baseline }}$, this is possible if and only if $C_{i, j}^{m t d}>C_{i, j}^{\text {unmet }}$. A possible explanation for this scenario is when no loads are dispatched to meet a need.

- Scenario 2: $U_{i, j}^{m t d}=U_{\text {baseline }}$, this is possible if and only if $C_{i, j}^{\text {mtd }}=C_{i, j}^{\text {unmet }}$. This scenario though possible is highly unlikely considering the wide disparity between $C_{i, j}^{\text {mtd }}$ and $C_{i, j}^{\text {unmet }}$.

- Scenario 3: $U_{i, j}^{m t d}>U_{\text {baseline }}$, this is possible if and only if $C_{i, j}^{m t d}<C_{i, j}^{\text {unmet }}$. This scenario is very likely especially as loads get dispatched to meet needs. Thus, an increase in $U_{i, j}^{\text {mtd }}$ is expected as $C_{i, j}^{\text {unmet }} \rightarrow C_{i, j}^{\text {Total-unmet }}$.

The computation of the associated cost of running the generator for an hour based on Table 7 is shown subsequently. Hourly fuel cost (assuming 1.6Litres/hour) is $\$ 0.76$ at $\$ 0.48 /$ Litre while emission from the generator for the hour is evaluated to be $3.8272 \mathrm{kgCO}_{2}$. Using $\$ 0.07 / \mathrm{kWh}$, the cost of emissions is computed to be $\$ 0.69$. The hourly maintenance fee (for 180 operations hours/month) translates to $\$ 0.03$. A total hourly cost of $\$ 1.48$ is thus obtained. The computation of $C_{i, j}^{\text {generator }}$ and $U_{i, j}^{\text {generator }}$ is shown in equations (5) - (6).

$$
\begin{aligned}
C_{i, j}^{\text {generator }} & =\frac{H_{i, j}}{\sum_{i} \sum_{j=1}^{4} H_{i, j}} \times 450.90 \\
U_{i, j}^{\text {generator }} & =U_{\text {baseline }}-\frac{C_{i, j}^{\text {generator }}-C_{i, j}^{\text {unmet }}}{C_{i, j}^{\text {Total-unmet }}}
\end{aligned}
$$

Table 8 presents the evaluated values from equations (5) - (6)

The plot of the various comfort levels for the utility and generator as well as the cost in dispatching needs $\mathrm{N}-1, \mathrm{~N}-2, \mathrm{~N}-3, \mathrm{~N}-4$ is shown in figure 1.

The huge costs involved in using generator as an alternative to the utility in meeting needs thus informs the need for a more affordable alternative system that is both cost effective and environmentally friendly. Furthermore, the proposed system must incorporate smart concepts that would enhance its operation and overall performance. 


\subsection{The proposed alternative energy system}

Figure 2 presents the proposed alternative system for meeting electricity needs of the household under consideration. It is observed from figure 2 that the proposed system consists of an inverter system (1 kVA), converter system (boost), battery (100 Ah, 24V), PV (2 x 80 $\mathrm{Wp}$ ) panel and a smart manager BLM-HEMS. The units (number) of the battery and PV panels are the maximum that can be afforded by the household.

The loads in the house are divided into two classes (Class 1 and Class 2) as shown in Table 12. BLM-HEMS provides a platform

$\checkmark$ For measuring weather condition (real time) to determine optimum operating condition of the converter. This is achieved through a hopping algorithm that is designed to track the maximum power point (MPPT) of the PV panel in real time by sampling results from either the incremental conductance method, perturb and observe method or normal operation (fixed duty cycle). The sampling duration of the converter is thus influenced based on the method that provides the maximum power.

$\checkmark$ For managing battery state of charge. Battery management is done to ensure that law of energy conservation is obeyed with battery discharge only allowed within the permitted limits.

$\checkmark$ Optimally dispatching Class 1 loads. In dispatching of loads under constrained supply, the optimal dispatch profile that results in better consumer comfort is always followed.

It must however be pointed out that the grid is never used in charging the battery. The methods for implementing the proposed alternative system described in figure 2 involve modelling of the PV system, converter system, battery management system and load dispatch. The detailed description of each method is presented subsequently.

\subsection{Photovoltaic modelling}

The typical equivalent circuit of a solar cell is shown in [39] where $\boldsymbol{I}_{\boldsymbol{s c}}$ is the current generated due to the photoelectric effect (i.e. solar radiation hitting the PV panel and causing electrons to be emitted and flow in the connected circuit), $\boldsymbol{I}_{\boldsymbol{D}}$ is the current that flows from the $\mathrm{p}$ junction to the $\mathrm{n}$ junction due to the diffusion of charge carriers, and is used to represent the net drop in the photo generated short circuit current $\left(\boldsymbol{I}_{\boldsymbol{S C}}\right), \boldsymbol{R}_{\boldsymbol{s} \boldsymbol{h}}$ is a resistor of high value that is used to represent losses due to defects in the PV panel, $\boldsymbol{R}_{\boldsymbol{s}}$ is the series resistor of low value used to represent losses due to the metal contacts that convey electrons, $\boldsymbol{R}_{\boldsymbol{L}}$ is the load resistance connected to the PV panel output, $\boldsymbol{I}$ is the load current i.e. the current that flows through the connected load $\boldsymbol{R}_{\boldsymbol{L}}$ and $\boldsymbol{V}$ is the terminal or load voltage (i.e. voltage across the load $\boldsymbol{R}_{\boldsymbol{L}}$ ). Newton-Raphson is employed in solving equation (7).

Given any $f(x)=y$, where $y$ is a linear homogeneous equation, if $\ni$ any $f\left(x_{o}\right)=0$ and $r$ is a suggested root where $x_{o}, r \in R$

Then, if $f(r) \neq 0$,

The distance $x_{o}-r=h$ can be reduced by updating $r$ to $r_{\text {new }}$ as follows:

$r_{\text {new }}=r-\frac{f(r)}{f^{\prime}(r)}, r=r_{\text {new }}$ while $h=x_{o}-r$ 
The stopping criterion is a problem of accuracy. If $f_{v}$ is the accuracy point and $h=-\frac{f(r)}{f^{\prime}(r)}$, the searching will stop when $a b s(h) \leq f_{v}$.

Thus if,

$I=n_{p} I_{s c}-n_{p} I_{s}\left(e^{q\left(V n_{s}+I R_{s} / n_{p}\right) / A K T_{c}}-1\right)-\frac{V n_{p} / n_{s}+I R_{s}}{R_{p}}$

Then,

$F(\mathrm{I})=I-n_{p} I_{s c}+n_{p} I_{s}\left(e^{q\left(V n_{s}+I R_{s} / n_{p}\right) / A K T_{c}}-1\right)+\frac{V n_{p} / n_{s}+I R_{s}}{R_{p}}$

Where $A$ is the ideality factor, $q$ is the charge, $K$ is the Boltzmann constant and $T_{c}$ is the $\mathrm{PV}$ cell temperature. The $\mathrm{I}-\mathrm{V}$ and $\mathrm{P}-\mathrm{V}$ performances under varying temperature and irradiance are shown in [40, 41].

\subsection{Converter model}

In modelling a suitable dc-dc boost converter for the proposed BLM-HEMS, a voltage source $\left(V_{i}\right)$ is utilized to represent a PV panel and a voltage controlled current source $\left(I_{p v}\left(V_{i}\right)\right)$ to represent the equivalent $\mathrm{PV}$ short circuit current generated through the photoelectric effect as shown in figure 3. Applying Kirchhoff's laws to figure 3 yields the state representation for both "ON" and "OFF" states.

During the "OFF" state, i.e. $S_{1}=0, r_{L} I_{L}+L \frac{d I_{L}}{d t}+V_{o}=V_{i}+r_{i}\left(I_{p v}-I_{L}\right)$. Re-arranging yields,

$\frac{d I_{L}}{d t}=\frac{1}{L} V_{i}-\frac{\left(r_{L}+r_{L}\right)}{L} I_{L}-\frac{1}{L} V_{o}-\frac{r_{i}}{L} I_{p v}\left(V_{i}\right)$

Similarly, for current at the input side, $I_{p v}\left(V_{i}\right)-C_{i} \frac{d V_{i}}{d t}=I_{L}$. Re-arranging yields,

$\frac{d V_{i}}{d t}=-\frac{1}{C_{i}} I_{L}+\frac{1}{C_{i}} I_{p v}\left(V_{i}\right)$

Also, at the output side, current is computed $I_{L}=C_{o} \frac{d V_{o}}{d t}+\frac{V_{o}}{R_{L}}$. Re-arranging yields,

$\frac{d V_{o}}{d t}=\frac{1}{C_{o}} I_{L}-\frac{1}{C_{o} R_{L}} V_{o}$

The equivalent state space equation is shown in equation (12) while figure 4 presents the equivalent circuit during the "OFF" state.

$\left[\begin{array}{c}\dot{V}_{i} \\ \dot{I}_{L} \\ \dot{V}_{o}\end{array}\right]=\left[\begin{array}{ccc}0 & -\frac{1}{C_{i}} & 0 \\ \frac{1}{L} & -\frac{\left(r_{i}+r_{L}\right)}{L} & -\frac{1}{L} \\ 0 & \frac{1}{C_{o}} & -\frac{1}{C_{o} R_{L}}\end{array}\right]\left[\begin{array}{l}V_{i} \\ I_{L} \\ V_{o}\end{array}\right]+\left[\begin{array}{l}\frac{1}{C_{i}} \\ \frac{r_{i}}{L} \\ 0\end{array}\right] I_{p v}\left(V_{i}\right)$ 
During the "ON" state, i.e. $S_{1}=1, V_{i}+\left(I_{p v}\left(V_{i}\right)-I_{L}\right) r_{i}=I_{L} r_{L}+L \frac{d I_{L}}{d t}$. Re-arranging yields,

$\frac{d I_{L}}{d t}=\frac{1}{L} V_{i}-\frac{\left(r_{i}+r_{L}\right)}{L} I_{L}+\frac{r_{i}}{L} I_{p v}\left(V_{i}\right)$

Similarly, $I_{p v}\left(V_{i}\right)-C_{i} \frac{d V_{i}}{d t}=I_{L}$. Re-arranging yields,

$\frac{d V_{i}}{d t}=-\frac{1}{C_{i}} I_{L}+\frac{1}{C_{i}} I_{p v}\left(V_{i}\right)$

At the output side, the capacitor is discharging and this yields $-C_{o} \frac{d V_{o}}{d t}=\frac{V_{o}}{R_{L}}$. Re-arranging yields,

$\frac{d V_{o}}{d t}=-\frac{1}{C_{o} R_{L}} V_{o}$

The equivalent state space equation for the "ON" state is shown in equation (16) while figure 5 presents the equivalent circuit during the "ON" state.

$$
\left[\begin{array}{c}
\dot{V}_{i} \\
\dot{I}_{L} \\
\dot{V}_{o}
\end{array}\right]=\left[\begin{array}{ccc}
0 & -\frac{1}{C_{i}} & 0 \\
\frac{1}{L} & -\frac{\left(r_{i}+r_{L}\right)}{L} & 0 \\
0 & 0 & -\frac{1}{C_{o} R_{L}}
\end{array}\right]\left[\begin{array}{l}
V_{i} \\
I_{L} \\
V_{o}
\end{array}\right]+\left[\begin{array}{l}
\frac{1}{C_{i}} \\
\frac{r_{i}}{L} \\
0
\end{array}\right] I_{p v}\left(V_{i}\right)
$$

Equation (17) presents the comprehensive equation that represents both the "ON" and "OFF" states based on the value of $a$ with $a=0$ during the "ON" state and $a=1$ during the "OFF" state. Figure $6(\mathrm{a}$ and $\mathrm{b})$ presents the transient and steady state response of the capacitor voltage and inductor current.

$$
\left[\begin{array}{c}
\dot{V}_{i} \\
\dot{I_{L}} \\
\dot{V_{o}}
\end{array}\right]=\left[\begin{array}{ccc}
0 & -\frac{1}{C_{i}} & 0 \\
\frac{1}{L} & -\frac{\left(r_{i}+r_{L}\right)}{L} & -\frac{a}{L} \\
0 & \frac{a}{C_{o}} & -\frac{1}{C_{o} R_{L}}
\end{array}\right]\left[\begin{array}{l}
V_{i} \\
I_{L} \\
V_{o}
\end{array}\right]+\left[\begin{array}{l}
\frac{1}{C_{i}} \\
\frac{r_{i}}{L} \\
0
\end{array}\right] I_{p v}\left(V_{i}\right)
$$

Table 10 presents the associated parameters for the PV panel, converter and battery utilized in modelling where $\eta_{P V}$ is PV efficiency, $r_{i}$ is internal resistance of input capacitor of capacitance $C_{i}, r_{L}$ is input side series resistance to inductor, $R_{L}$ is load resistance, $F_{s}$ is sampling frequency of the converter, $k$ is duty cycle of converter, $C_{o}$ is capacitance of output capacitor, $L$ is inductance of input inductor, $\eta_{b a t t}$ is battery efficiency, DOD is depth of discharge of battery, $\sigma$ is the monthly self-discharge rate of battery, $V_{m p}$ is the maximum 
power voltage for the PV panel, $I_{m p}$ is the maximum power current for the PV panel and $\eta_{i n v}$ is inverter efficiency. Other associated costs include generator initial purchase cost $(\$ 491.80)$, installation cost (\$81.97) and lifecycle (5000 hours). Table 11 presents the detailed costs (initial purchase, installation etc.) and hourly operations for PV/battery, Utility and Generator. For further reading on converter design and modelling including the different topologies, refer to [42-44].

\subsection{Maximum Power Point Tracking}

Generally, the output of photovoltaic generation systems (PGS) are influenced directly by varying solar irradiance and ambient temperature. Coupled with the problem of shading, it thus becomes necessary to operate PGS at maximum power [45]. Historically, mechanical systems were first developed to move solar panels in order to get maximum solar radiation while subsequent designs known as electrical MPPT utilized the operating voltage/current profile of solar panels to adjust converter switching frequency for maximum power tracking [46]. PV systems are designed to operate at maximum output power levels for any solar irradiance intensity and temperature with their load impedance determining their output power. To provide for operational control, a DC/DC converter is inserted between the PV panel and the batteries with the PV panel array forming the input to the DC/DC converter and the batteries and load forming its output. With the DC/DC converter acting as an impedance matching circuit, a computing system can modify the duty cycle (and implicitly the input impedance of the DC/DC converter) until the system reaches maximum power point (MPP) [46].

Various MPPT techniques such as fixed duty cycle, beta method, hill climbing/perturb and observe, incremental conductance, constant voltage and current, fuzzy logic controller etc. have been extensively discussed by [47]. A current perturbation algorithm (CPA) with a variable perturbation step and fractional short circuit current algorithm (FSCC) was proposed by [48] to determine an optimum operating current. Furthermore, [49] applied a radial basis function network-sliding mode (RBFNSM) and a general regression neural network (GRNN) for MPPT control. For wind application, there was a 5.7\% improvement in performance over the PI control mechanism with power extraction efficiency of $84 \%$ and a transient time response of 0.3 second. Similarly, [49] achieved a 15\% improvement over the perturb and observe method with a transient response time of 0.09 second for PV applications. Other applications of novel MPPT algorithms include [50] where a hybrid power control system (consisting of the Wilcoxon RBFN and the improved Elman neural network) for grid connected hybrid power generation system was proposed, [51] where a fuzzy-logic-based voltage-regulated solar MPPT system for hybrid power systems was proposed and [52] that developed a high performance neuro-fuzzy indirect wavelength-based adaptive MPPT control for PV systems.

In tracking maximum power point (MPP) for this work, a hopping algorithm is developed. The hopping algorithm evaluates maximum solar power based on a modified incremental conductance method, perturb and observe method and normal operation. The maximum value in real-time is chosen and used in adjusting the duty cycle of the converter. There have been extensive discussions on incremental conductance and perturb and observe methods in literature [53-59]. From figure 7, the monitoring of the behaviour of $\frac{d P}{d V}$ is a trigger for adjusting the converter duty cycle (in incremental conductance) while the successive difference between power $P_{t}-P_{t-1}$ is used in adjusting voltage in perturb and 
observe method. The slight modification added to the incremental conductance method is in the converter duty cycle variation. Rather than varying the sampling time for the "ON" state using a fixed step value, i.e. $t_{O N}=t_{O N} \pm \Delta$, "ON" state time is varied using a varying fraction of $t_{O N}$ to produce $t_{O N}=t_{O N} \pm\left(f r a c \times t_{O N}\right)$. The hopping algorithm is further described in Algorithm 1.

\subsection{Battery management}

The internal working structure of BLM-HEMS is shown in figure 8. The state of charge of the battery $\operatorname{SOC}(t)$ at any time $t$ is defined as the charge quantity in the battery at the time $t$ and is defined/bounded as:

$$
S O C_{\min } \leq S O C(t) \leq S O C_{\max }
$$

The minimum charge quantity $\left(S O C_{\min }\right)$ is a function of the DOD, i.e. $S O C_{\min }=f(D O D)$ which implies that $S O C_{\min }=(1-D O D) \times C_{\text {batt }}$, with $S O C(t)=S O C_{\max }$ at maximum charge $C_{\text {batt }}$, where $C_{\text {batt }}$ is the capacity of the battery (100 Ah). Under operation of the PV panel, 3 possibilities could occur.

$\checkmark$ Case 1: $D_{i}(t)<E_{P V}(t)$ which would result in battery charging.

$\checkmark$ Case 2: $D_{i}(t)=E_{P V}(t)$ which would result in $\operatorname{SOC}(t)=\operatorname{SOC}(t) \times(1-\sigma)$

$\checkmark$ Case 3: $D_{i}(t)>E_{P V}(t)$ which could result in either battery charging or discharging.

Where $E_{P V}(t)$ is the PV panel power output at time $t$ and $D_{i}(t)$ is the time $t$ demand. The battery management function of the BLM-HEMS is to ensure that equation (19) is always maintained for the simulation period (1 day) where $S O C\left(t_{\text {initial }}\right)$ is the battery state of charge at the beginning of simulation time and $\operatorname{SOC}\left(t_{\text {final }}\right)$ is the battery state of charge at end of simulation.

$$
\operatorname{SOC}\left(t_{\text {initial }}\right)=\operatorname{SOC}\left(t_{\text {final }}\right)
$$

\subsubsection{Battery charge and discharge models}

Battery charging occurs during Case 1 and in Case 3 when the eventual allocation/dispatch of load results in only a fraction of $E_{P V}(t)$ being utilized. During excess power generation from the PV panel as presented by Case 1, the excess power $\operatorname{Sup}(t)=E_{P V}(t)-D_{i}(t)$ gets dumped into the battery as shown in equation (20). Charging in Case 3 as a result of $\alpha E_{P V}(t)$ being dispatched also follows equation (20) where $0<\alpha<1$.

$$
\operatorname{SOC}(t)=\operatorname{SOC}(t-1) \times(1-\sigma)+\left(\operatorname{Sup}(t) \times \eta_{\text {batt }}\right)
$$

Given $\operatorname{def}(t)=D_{i}(t)-E_{P V}(t)$ to be the deficit power needed from the battery for hour $t$ due to insufficient PV power, then $\overline{\operatorname{def}(t)}=\frac{\operatorname{def}(t)}{\eta_{\text {inv }} \times \eta_{\text {batt }}}$ is defined and any of the following discharge types can occur.

$$
\begin{aligned}
& \checkmark \text { Type } \quad 1: \quad S_{\min } \leq \overline{\operatorname{def}(t)}<\operatorname{SOC}(t-1) \times(1-\sigma) \quad \text { in } \quad \text { which } \quad \text { case } \\
& \quad \operatorname{SOC}(t)=\operatorname{SOC}(t-1) \times(1-\sigma)-\overline{\operatorname{def}(t)} \\
& \checkmark \text { Type 2: } \operatorname{SOC}(t-1) \times(1-\sigma)<\overline{\operatorname{def}(t)} \text { in which case }
\end{aligned}
$$




$$
S O C(t)=S O C_{\min }
$$

Further reading on battery systems and management especially for stand-alone PV systems is found in [60].

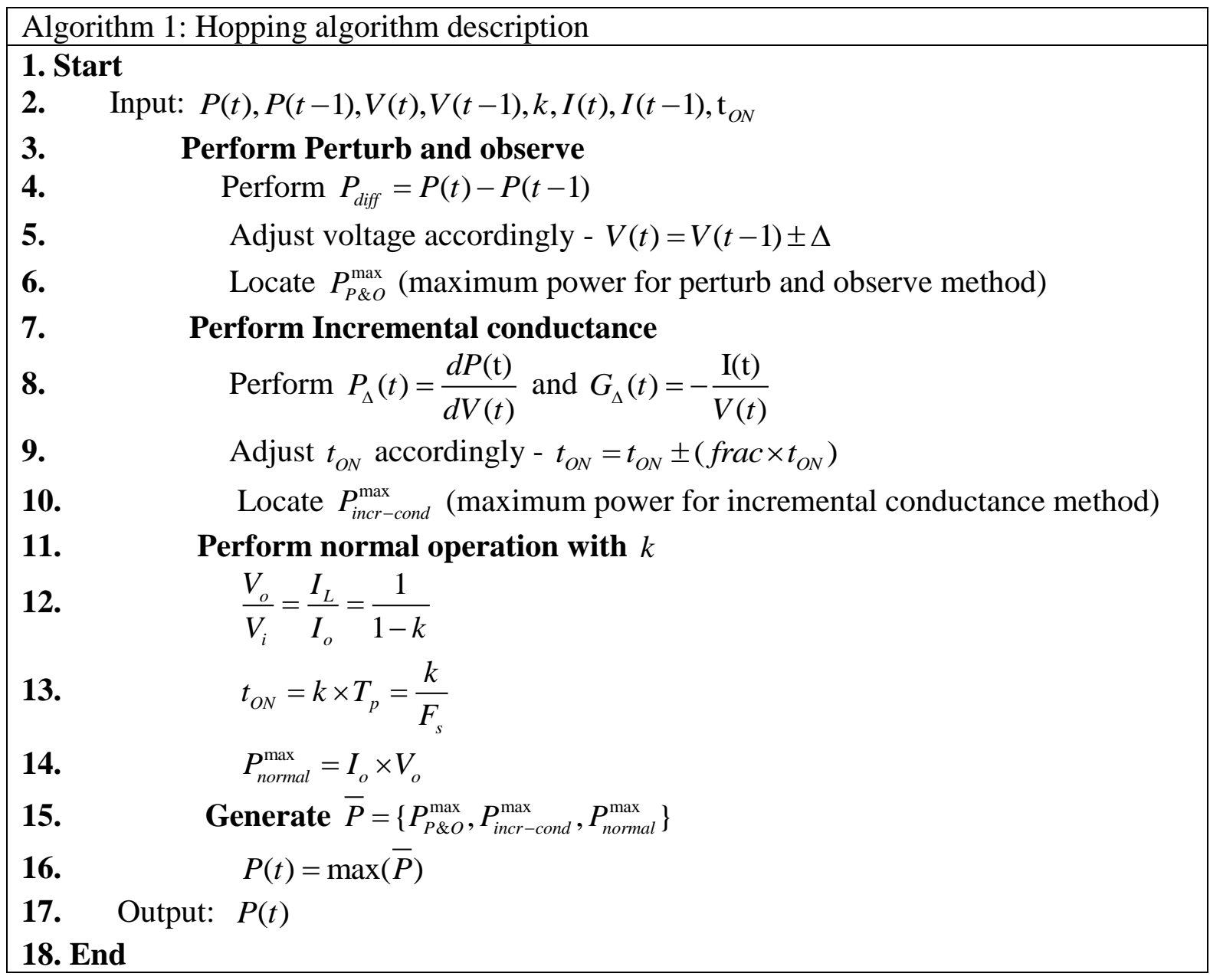

Figure 9 presents the simplified low chart depicting the general BLM-HEMS flow and operation.

\subsection{Results and discussion}

A typical 2-bedroom residential flat in a low-cost housing estate in Lagos (SouthWest, Nigeria) is considered. The choice of Lagos is due to the high prevalence of generators within the city [10]. The low-cost flat is assumed to house a family of 4 , comprising of the father, mother and children. The combined annual income of the household is 1,200,000 Naira (\$6557.38) which translates to a monthly income of 167,000 Naira $(\$ 546.45)$. The monthly income of the family puts them above the poverty line of 55,000 Naira (\$180.33) per year [9]. Table 12 presents a typical audit of the major expected electrical appliances in the house with Table 13 providing a further breakdown to the classification of grouped loads in Table 12. From Table 12, assuming a 0.85 demand factor (df) which is closely similar to [31], the peak consumption of the house is estimated to be around $4000 \mathrm{Wh}$ which is usually at weekends from $7 \mathrm{pm}-9 \mathrm{pm}$. The location of the low-cost house (Ikeja) means that Ikeja 
Electricity Distribution Company (IKEDC) is responsible for billing the case study house. The case study house has a single-phase 240 VAC pre-paid electric meter installed. Based on the prevailing tariff system prescribed by the electricity regulator - NERC (Nigerian Electricity Regulatory Commission) through the multi-year tariff order (MYTO) II, the per unit electricity rate is charged at 21.30 Naira (\$0.07) per kilowatt-hour. No additional standing charges are billed the customer.

The tracking of maximum power using perturb and observe, incremental conductance, normal operation and hopping algorithm is shown in figure 10. As seen in figure 10, the hopping algorithm vacillates between the incorporated methods in determining the possible maximum power and adjusting the duty cycle of the converter (shown in fig 12). The overall efficiency in terms of maximum power tracking for a day is $70.90 \%, 67.59 \%, 66.36 \%$ and $72.20 \%$ for normal, perturb and observe, incremental conductance and hopping algorithms respectively. This implies that the hopping algorithm achieves an extra $7 \%$ and $9 \%$ efficiency in terms of MPPT over perturb and observe and incremental conductance methods respectively. These values compare favourably with the $15 \%$ improvement in terms of MPPT by [49].

The transient behaviour for the various MPPT methods is observed in the figure 11 for a 4 seconds window with smaller resolution. Figure 12 shows a snippet of the overall firing sequence of the converter (i.e. the state - ON/OFF of the converter during MPPT) for the various MPPT algorithms. As seen, a similar ON/OFF state sequence is noticed for the perturb and observe and incremental conductance methods which is at variance with the normal operation (No MPPT) of the converter (using fixed duty cycle).

A major impediment to the MPPT tracking by the perturb and observe methods and the incremental conductance method is the rapid change in solar irradiance level which necessitates for rapid adjustment of converter duty cycle and could lead to over or under compensation. However, during stable operations at high power output $(>100 \mathrm{~W})$, the perturb and observe and the incremental conductance methods outperform the normal operation with efficiency of up to $95 \%$.

The sizing of the PV/battery system was done for only one day with the battery initial charge set to $10 \%$ (being the lowest discharge capacity of the battery). The demerit of this set up thus means that demands from $8 \mathrm{pm}$ till $7 \mathrm{am}$ will hardly be dispatched by the PV/battery setup. Demands that will be mostly dispatched (depending on the available number of sunshine hours) are demands within the hours from $4 \mathrm{pm}$ till $8 \mathrm{pm}$. The analysis of dispatch and comparison of associated costs and comfort will thus centre around dispatch occurring within the hours $4 \mathrm{pm}$ till 8pm. Considering the two major seasons in Nigeria (dry and wet seasons), the simulation was run with sunshine data to represent on average, the daily irradiance for both wet season (April to October) and dry season (November to March).

Table 14 presents the demand for the hours $(4 \mathrm{pm}$ till $8 \mathrm{pm})$ under consideration that are to be dispatched from PV/battery/utility configuration depending on PV/battery capacity and utility (grid) availability. A justification for the selected hours under consideration is found in [61] who opines that the selected hours under consideration form a sub-set of the typical hours of peak demand for low/middle income households. From Table 14, $340 \mathrm{Wh}$ is demanded from $4 \mathrm{pm}-5 \mathrm{pm}, 385 \mathrm{Wh}$ is demanded for $5 \mathrm{pm}-6 \mathrm{pm}, 409 \mathrm{Wh}$ is demanded from6pm $-7 \mathrm{pm}$ and $396 \mathrm{Wh}$ is demanded from $7 \mathrm{pm}-8 \mathrm{pm}$. Total demand for the time 
spanning $4 \mathrm{pm}-8 \mathrm{pm}$ is $1530 \mathrm{Wh}$. The $\mathrm{N}-1, \mathrm{~N}-2, \mathrm{~N}-3$ and $\mathrm{N}-4$ needs computation for $4 \mathrm{pm}$ till $8 \mathrm{pm}$ as well as the appliances selected for dispatch by the user and the eventual wattage of the appliances dispatched are shown in Table 15. It is seen from Table 15 that utility though available for hours $4 \mathrm{pm}-7 \mathrm{pm}$, is not utilized in dispatching any selected load from $4 \mathrm{pm}$ till $5 \mathrm{pm}$.

However, from $5 \mathrm{pm}$ till $7 \mathrm{pm}$ when PV/battery capacity becomes insufficient, the utility supplies the shortfall of $4.70 \mathrm{Wh}(5 \mathrm{pm}-6 \mathrm{pm})$ and $367.63 \mathrm{Wh}(6 \mathrm{pm}-7 \mathrm{pm})$. Total PV power supplied from $4 \mathrm{pm}$ till $8 \mathrm{pm}$ is $310.68 \mathrm{Wh}$ while battery supply within the same time span is $453.33 \mathrm{Wh}$ with the utility supplying $372.33 \mathrm{Wh}$ from $4 \mathrm{pm}$ till $8 \mathrm{pm}$. Demand unmet within the time from $4 \mathrm{pm}$ till $8 \mathrm{pm}$ is $396 \mathrm{Wh}$ and occurs particularly within $7 \mathrm{pm}-8 \mathrm{pm}$ when $\mathrm{PV} / \mathrm{battery}$ is insufficient and utility is unavailable. Table 16 presents a detailed description of Table 15 in terms of $H_{i, j}, U_{i, j}^{P V / b a t t e r y}, C_{i, j}^{\text {unmet }}$ and savings (nominal) where the nominal savings represent the real savings in actual money terms based on a reduction in utility billing as a result of the dispatch of load from an alternative energy source. All computed values are for a typical day.

The computation of $U_{i, j}^{P V / b a t t e r y}$ in Table 16 shows the direct relationship that exists between $U_{i, j}^{P V / b a t t e r y}$ and $C_{i, j}^{\text {unmet }}$. For any dispatch of loads (appliances) to meet needs that incurs $C_{i, j}^{\text {unmet }}$, then a corresponding drop in $U_{i, j}^{P V / b a t t e r y}$ is expected. The insufficiency of PV/battery capacity for time spanning $6 \mathrm{pm}-8 \mathrm{pm}$ leads to a corresponding decrease in $U_{i, j}^{P V / b a t t e r y}$ with $U_{i, j}^{\text {PV/battery }}$ going below $U_{\text {baseline }}$ from $6 \mathrm{pm}$.

The battery state of charge during the simulation period is shown in figure 13. It is observed from figure 13 that the battery mainly charges from $8 \mathrm{am}$ till $4 \mathrm{pm}$ when it starts being discharged. Its maximum charge capacity in terms of power for the day is $780.64 \mathrm{~W}$ (65.1\% of its maximum capacity) and this occurs at $4 \mathrm{pm}$. SOC $\left(\mathrm{t}_{\text {initial }}\right)$ is $10 \%$ and $\operatorname{SOC}\left(\mathrm{t}_{\text {final }}\right)$ is $10.8 \%$ which satisfies the law of energy conservation. The battery is solely charged from the PV panel with the grid (utility) only coming in (when available) to offset unmet demand. The operational behaviour of the PV/battery/utility system alongside demand and dispatch profile for the day is shown in figure 14. It is observed from figure 14 that total demand within the day (including the specific hours under consideration) is $4420 \mathrm{Wh}$ of which 2161 Wh went unmet (due to utility unavailability and insufficient PV/battery capacity). Utility supply within the day is $1496.60 \mathrm{Wh}$, PV effective supply (excluding battery charging) is 308.96 Wh while battery supply is $453.44 \mathrm{Wh}$. Utility supply was unavailable for 11 hours within the day of which 7 were during periods of demand.

In standardizing Tables 15 and 16, there is the need to compare the results obtained for utility with PV/battery and generator as alternatives in terms of associated costs, carbon footprint and return on investment (RoI). Table 17 presents the daily, monthly and yearly cost of dispatch for the effective demand (demand during utility availability) for $\mathrm{PV} /$ battery/utility, utility only and Utility/generator. It is seen from Table 17 that for a daily demand of $4420 \mathrm{Wh}$, the daily effective demand is $2269 \mathrm{Wh}$ (with 7 hours of grid available during the demand hours). While 48.12 Naira (\$0.16) is spent daily dispatching $2269 \mathrm{Wh}$, 31.89 Naira (\$0.10) is spent dispatching same demand for PV/battery/utility representing a $33.7 \%$ savings. Using the Utility/generator option results in a daily expenditure of 3,198 
Naira (\$10.49) which translates to $1,167,390$ Naira (\$3828) in a year.

In terms of RoI, the initial cost of purchase and installation for the PV/battery is repaid within 25 years with 6000 Naira $(\$ 19.67)$ yearly savings of the PV/battery/utility option over Utility only option (for the adopted hourly electricity cost of $\$ 21.30 / \mathrm{kWh}$ ). Any outstanding cost however is due to the battery replacement and yearly maintenance within the 25 years. Table 18 presents the equivalent carbon emissions for (PV, battery, utility and the generator) and is used in computing the carbon emissions for PV/battery/utility, Utility only and Utility/generator options (shown in Table 19). In addition to generating the lowest cost for electricity dispatch, the $\mathrm{PV} / \mathrm{battery} /$ utility option also has the lowest daily carbon emissions $\left(1.179 \mathrm{kgCO}_{2}\right)$ compared with $1.588 \mathrm{kgCO}_{2}$ (Utility only) and $28.384 \mathrm{kgCO}_{2}$ (Utility/generator).

The comparison of evaluated $U_{i, j}^{\text {utility }}, U_{i, j}^{P V / b a t t e r y / \text { utility }}$ and $U_{i, j}^{\text {utility/generator }}$ for the hours $4 \mathrm{pm}-5 \mathrm{pm}, 5 \mathrm{pm}-6 \mathrm{pm}, 6 \mathrm{pm}-7 \mathrm{pm}$ and $7 \mathrm{pm}-8 \mathrm{pm}$ is shown in the figures $15-18$ for $\mathrm{N}-1$, $\mathrm{N}-2, \mathrm{~N}-3$ and N-4 needs. The superiority of the PV/battery/utility configuration is shown in figures 15,16 and 18 where it achieves average hourly comfort levels ( $U_{\text {avg }}^{\text {PV/battery/utility }}$ ) of 5.68 $(4 \mathrm{pm}-5 \mathrm{pm}), 5.58(5 \mathrm{pm}-6 \mathrm{pm})$ and $4.97(7 \mathrm{pm}-8 \mathrm{pm})$ compared with 5.32, 5.32 and 4.24 respectively for Utility only option. Another observation is that the PV/battery/utility configuration shows a better integration and seamless operation than the Utility/generator configuration. This observation is better explained in figure 19 which presents the graduation of the hourly cost of dispatching electricity for Utility only, PV/battery/utility and Utility/generator. A common observation from figure 19 is the fact that $U_{i, j}^{\text {utility }}$ increases as the hourly electricity dispatch cost difference between Utility only and PV/battery/utility configuration increases. From $4 \mathrm{pm}-5 \mathrm{pm}$, the difference in hourly electricity dispatch cost between Utility only (7.24 Naira, \$0.02) and PV/battery/utility (0.29 Naira, \$0.00) which is 6.95 Naira (\$0.02) results in $U_{\text {avg }}^{P V / \text { battery/utility }}=5.68$ while for $5 \mathrm{pm}-6 \mathrm{pm}$ the hourly electricity dispatch cost difference of 7.81 Naira $(\$ 0.03)$ results in $U_{\text {avg }}^{P V / b a t t e r y / u t i l i t y}=5.58$. However, for $6 \mathrm{pm}-7 \mathrm{pm}$, the hourly electricity dispatch cost of 0.59 Naira $(\$ 0.00)$ results in $U_{\text {avg }}^{\text {utility }}=5.59$.

The summary of the associated statistics for Utility only, PV/battery/utility and Utility/generator configurations for $4 \mathrm{pm}-8 \mathrm{pm}$ is shown in Table 20. In expatiating on figures 15 to 18 , Table 20 provides at a glance the $C_{i, j}^{\text {mtd }}, U_{\text {avg }}^{m t d}$, utility status (available or unavailable), PV/battery capacity (sufficient or insufficient) and demand for each hour between $4 \mathrm{pm}-8 \mathrm{pm}$. This is useful in evaluating quickly the performance of each configuration hourly and the best dispatch configuration in terms of selection.

\subsection{Sensitivity analysis}

From the results obtained, the PV/battery/utility option achieves a yearly savings of about 6000 Naira using utility electricity charge of $21.30 / \mathrm{kWh}$. However, since electricity prices vary across Nigeria based on the distribution company serving a state, we run sensitivity analysis for $\$ 25.00 / \mathrm{kWh}, \$ 30.00 / \mathrm{kWh}$ and $\$ 50.00 / \mathrm{kWh}$ with fixed solar production levels and $0 \%$ increment in electricity hourly cost by the utility to determine the effect of hourly electricity cost in influencing RoI. Table 21 presents the yearly electricity cost for Utility only and PV/battery/utility options including their yearly savings and payback period for varying hourly cost of electricity. It is observed from Table 21 that for $\$ 25.00 / \mathrm{kWh}$, the yearly savings of $\$ 6715$ (\$22.02) translates to a payback time of about 21 
years. Similarly, for $\$ 30.00 / \mathrm{kWh}$, the yearly savings of $\$ 7395$ (\$24.24) results in a payback time of 16 years with $\$ 50.00 / \mathrm{kWh}$ resulting in yearly savings of $\$ 10112$ and an eventual payback time of about 8.4 years.

The implication of this sensitivity analysis is that across Nigeria, different states with varying hourly costs of electricity have varying potential payback periods. This thus implies that in encouraging the adoption of the PV/battery/utility option, there should be an incentive to the buyer which shows significant potential savings over a reasonable time. Furthermore, while this sensitivity analysis has only examined the effect of hourly electricity cost on payback period computation, advancements in solar PV efficiency imply that there could be further reduction in payback period thus making the adoption of PV/battery/Utility option quite attractive. The attractiveness of the PV/battery/Utility option notwithstanding, solar irradiance plays a crucial role as its stochasticity can increase the payback period invariably making the utility/generator or Utility only options better alternatives.

In benchmarking the results obtained in this work, the savings obtained in [3] show that annual savings on electricity bills was about $38 \%$. For this work, it is seen from Table 21 that annual savings vary from $34 \%$ (at $\$ 21.30 / \mathrm{kWh}$ ), $52 \%$ (at $\$ 23.00 / \mathrm{kWh}$ ), $56 \%$ (at $\$ 25.00 / \mathrm{kWh}$ ) to $64 \%$ (ta $\$ 30.00 / \mathrm{kWh}$ ) for the considered loads. Furthermore, in terms of peak demand reduction, Table 15 shows that BLM-HEMS achieves an average peak demand reduction of $52 \%$ for the time between $4 \mathrm{pm}-8 \mathrm{pm}$ compared with $42 \%$ peak time electricity demand reduction in [3]. The cumulative effect of the peak demand reduction thus implies that the utility can take advantage of BLM-HEMS (as a demand response mechanism) for targeted areas to shave peak demand as also posited in [3] where it was argued that the savings is of more advantage to the utility. The benefits of the significant reduction in peak demand implies that the utility has improved utilization of its supply capacity and can optimally dispatch its generators at reduced operations cost. Furthermore, the utility can balance demand/supply with minimized reserve margins [62].

\subsection{Policy discussions for improving the adoption of BLM-HEMS}

Energy poverty in Nigeria is both a problem of access (primarily) and mobility (i.e. the ability of households to increase their electricity consumption either by increasing electrical appliances owned or extending the duration of usage of already owned electrical appliances). As noted in [4], there was limited usage of solar PV systems. This is not unusual owing to the huge costs involved in initial purchase and for subsequent upgrades. In order therefore to improve the ownership of more solar PV systems across households, government could implement an additional surcharge for fossil-based electricity generation. This cost which is billed the utility would invariably be transferred to the consumers through higher electricity costs. With higher electricity costs, there is more incentive for households to consider adopting a hybrid system.

However, while the government implements a fossil-based tax on the utility, it must ensure that policy is put in place to reduce the cost of purchase of solar PV systems. According to [1], the government could explore options such as tax exemption for imported solar PV products and financing options for their purchase. Also, considering the need for technical expertise in their set up, government should also encourage the training of skilled manpower necessary for the installation, maintenance and repair of these systems. 


\subsection{Conclusions}

A biased load manager home energy management system (BLM-HEMS) has been proposed and modelled in dispatching specific loads for low income consumers, using low cost buildings in Lagos, South-West Nigeria. The users' electricity appliances have been classified accordingly with the BLM-HEMS which provides an interface for integrating the grid and alternative power system for load dispatch. Based on the maximum amount users are willing to spend, analysis has been conducted to investigate the best configuration (alternative power source) that would lead to an improvement in occupants' comfort level while reducing their electricity bill and carbon footprint.

Results obtained show that the PV/battery/utility configuration offers the best option due to its low yearly maintenance cost, reduced carbon emissions and improvement in consumer comfort compared to the Utility only and Utility/generator configurations. Results have also established that although the Utility/generator configuration is capable of meeting entirely the needs of the user daily, its high operations and maintenance cost coupled with its high carbon footprint decimate drastically any potential savings accrued from its dispatch of occupants' needs. Furthermore, the peculiarity of utility availability in Nigeria (frequent grid interruptions) makes the Utility only option a poor choice owing to the lack of an alternative to offset demand during grid interruptions.

The daily savings of the PV/battery/utility configuration over the Utility only configuration for hourly electricity cost of $\mathrm{N} 21.30 / \mathrm{kWh}$ is about $34 \%$ with a $26 \%$ reduction in carbon emissions by the PV/battery/utility configuration over the Utility only configuration. The yearly savings of the PV/battery/utility configuration of about 6000 Naira (\$19.67) translates to about $4 \%$ of the cost of initial PV/battery purchase and installation. This implies that the PV/battery/utility configuration can repay the initial purchase and installation costs within 25 years excluding yearly maintenance and battery replacements. In terms of daily usage, the proposed BLM-HEMS is not intended to be complicated as it is envisaged to be interoperable with existing solar PV systems. However, a discrimination of household load points is necessary for easy application of the load allocation component of the BLM-HEMS.

The sensitivity analysis carried out has shown that the adopted BLM-HEMS reacts favourably to higher hourly electricity cost from the utility with potential annual electricity savings of up to $64 \%$ and a payback period of 8.4 years. This value exceeds the reported savings in [3] which shows the viability of the proposed BLM-HEMS. Furthermore, the 4\% improvement in comfort level for the house also implies that the systems multi-objectives are fully meant. The BLM-HEMS is thus capable of mitigating poverty in households since it guarantees savings for households which can be utilized for other activities or for extending the utilization time of already owned electrical appliances. The BLM-HEMS thus improves the application of solar PV systems beyond basic household needs as presented in [4], by ensuring that yearly savings from the PV/battery/utility option can be utilized in upgrading households SHS for increased solar PV participation in household electricity generation. This implies that such households can engage in other economic activities beyond basic household needs due to improvement in electricity access. This study can be useful for better understanding of on-grid/off-grid home energy systems which are instrumental for future energy planning and incentive analysis in developing countries, including Nigeria. 
Future research would be to investigate the effect of load ownership and duration of use on the comfort level and productivity of households. This is necessary to help provide low/middle income households an improved guide to owning electrical appliances that will lead to improvement in their quality of life and overall productivity.

\subsection{Acknowledgements}

The first author acknowledges the financial assistance of the National Research Foundation (NRF) and The World Academy of Sciences (TWAS) through the DST-NRFTWAS doctoral fellowship towards this research. Opinions expressed and conclusions arrived at, are those of the authors and are not necessarily to be attributed to the NRF. The three anonymous reviewers are also acknowledged for their helpful comments.

\section{References}

1. Monyei, C.G., et al., Nigeria's energy poverty: Insights and implications for smart policies and framework towards a smart Nigeria electricity network. Renewable and Sustainable Energy Reviews.

2. $\quad$ United Nations Sustainable development Goals [Online]. [cited 2017 29-Aug-2017]; Available from: http://www.un.org/sustainabledevelopment/sustainable-developmentgoals/.

3. Naspolini, H.F. and R. RÃ $\tilde{\mathrm{T}}^{1 / 4}$ ther, Assessing the technical and economic viability of low-cost domestic solar hot water systems (DSHWS) in low-income residential dwellings in Brazil. Renewable Energy. 48: p. 92-99.

4. Stojanovski, O., M. Thurber, and F. Wolak, Rural energy access through solar home systems: Use patterns and opportunities for improvement. Energy for Sustainable Development. 37: p. 33-50.

5. Gautam, A., et al., A review on technical improvements, economic feasibility and world scenario of solar water heating system. Renewable and Sustainable Energy Reviews. 68: p. 541-562.

6. Ming-Zhi Gao, A., et al., Sustainable photovoltaic technology development: step-bystep guidance for countries facing PV proliferation turmoil under the feed-in tariff scheme. Renewable and Sustainable Energy Reviews. 43: p. 156-163.

7. National Poverty Rates for Nigeria: 2003-04 (Revised) and 2009-10 (Abridged Report) [Online], National Bureau of Statistics.

8. Consumption pattern in Nigeria 2009/10 (Preliminary Report). 2012, National Bureau of Statistics.

9. General Household Panel Survey Wave 2 2012/13, National Bureau of Statistics.

10. Annual Abstract of Statistics. 2012, National Bureau of Statistics.

11. Chekired, F., et al., An Energy Flow Management Algorithm for a Photovoltaic Solar Home. Energy Procedia. 111: p. 934-943.

12. Ciabattoni, L., et al., Design of a Home Energy Management System by Online Neural Networks. IFAC Proceedings Volumes. 46(11): p. 677-682.

13. Iwafune, Y., et al., Energy-saving effect of automatic home energy report utilizing home energy management system data in Japan. Energy. 125: p. 382-392.

14. Choi, D.-H. and L. Xie, A framework for sensitivity analysis of data errors on home energy management system. Energy. 117: p. 166-175.

15. Honold, J., et al., Distributed integrated energy management systems in residential buildings. Applied Thermal Engineering. 114: p. 1468-1475. 
16. J. Louis, A.C., K. Leiviska and E. Pongracz, Environmental Impacts and Benefits of Smart Home Automation: Life Cycle Assessment of Home Energy Management System, in International Federation of Automatic Control. 2015, Elsevier. p. 880-885.

17. Jin, X., et al., Foresee: A user-centric home energy management system for energy efficiency and demand response. Applied Energy.

18. Abushnaf, J., A. Rassau, and W.o. GÃ³nisiewicz, Impact of dynamic energy pricing schemes on a novel multi-user home energy management system. Electric Power Systems Research. 125: p. 124-132.

19. Beaudin, M. and H. Zareipour, Home energy management systems: A review of modelling and complexity. Renewable and Sustainable Energy Reviews. 45: p. 318335.

20. Clastres, C., et al., Ancillary services and optimal household energy management with photovoltaic production. Energy. 35(1): p. 55-64.

21. Mohsenian-Rad, A.H., et al., Autonomous Demand-Side Management Based on Game-Theoretic Energy Consumption Scheduling for the Future Smart Grid. IEEE Transactions on Smart Grid. 1(3): p. 320-331.

22. Duy Long, H., F.F.d. Lamotte, and H. Quoc Hung. Real-time dynamic multilevel optimization for Demand-side Load management. in 2007 IEEE International Conference on Industrial Engineering and Engineering Management. 2007.

23. Matallanas, E., et al., Neural network controller for Active Demand-Side Management with PV energy in the residential sector. Applied Energy. 91(1): p. 90-97.

24. Mets, K., et al. Exploiting V2G to optimize residential energy consumption with electrical vehicle (dis)charging. in 2011 IEEE First International Workshop on Smart Grid Modeling and Simulation (SGMS).

25. Agnetis, A., et al., Load Scheduling for Household Energy Consumption Optimization. IEEE Transactions on Smart Grid. 4(4): p. 2364-2373.

26. Molderink, A., et al. Domestic energy management methodology for optimizing efficiency in Smart Grids. in 2009 IEEE Bucharest PowerTech. 2009.

27. Hassan Naveed U1, P.M.A., Yuen Chau, Huang Shisheng and Wang Xiumin, Impact of scheduling flexibility on demand profile flatness and user inconvenience in residential smart grid system. Energies, 2013. 6(12): p. 6608-35.

28. Bozchalui, M.C., et al., Optimal Operation of Residential Energy Hubs in Smart Grids. IEEE Transactions on Smart Grid. 3(4): p. 1755-1766.

29. Conejo, A.J., J.M. Morales, and L. Baringo, Real-Time Demand Response Model. IEEE Transactions on Smart Grid. 1(3): p. 236-242.

30. Mohsenian-Rad, A.H. and A. Leon-Garcia, Optimal Residential Load Control With Price Prediction in Real-Time Electricity Pricing Environments. IEEE Transactions on Smart Grid. 1(2): p. 120-133.

31. Ogunjuyigbe, A.S.O., T.R. Ayodele, and C.G. Monyei, An intelligent load manager for PV powered off-grid residential houses. Energy for Sustainable Development. 26: p. 34-42.

32. Ogunjuyigbe, A.S.O., C.G. Monyei, and T.R. Ayodele, Price based demand side management: A persuasive smart energy management system for low/medium income earners. Sustainable Cities and Society. 17: p. 80-94.

33. Salinas, S., M. Li, and P. Li, Multi-Objective Optimal Energy Consumption Scheduling in Smart Grids. IEEE Transactions on Smart Grid. 4(1): p. 341-348.

34. Ogunjuyigbe, A.S.O., T.R. Ayodele, and O.A. Akinola, User satisfaction-induced demand side load management in residential buildings with user budget constraint. Applied Energy. 187: p. 352-366. 
35. Ayodele, T.R. and A.S.O. Ogunjuyigbe, Increasing household solar energy penetration through load partitioning based on quality of life: The case study of Nigeria. Sustainable Cities and Society. 18: p. 21-31.

36. Ogunjuyigbe, A.S.O., T.R. Ayodele, and O.A. Akinola, Optimal allocation and sizing of PV/Wind/Split-diesel/Battery hybrid energy system for minimizing life cycle cost, carbon emission and dump energy of remote residential building. Applied Energy. 171: p. 153-171.

37. Ogunjuyigbe, A.S.O., T.R. Ayodele, and O.E. Oladimeji, Management of loads in residential buildings installed with $P V$ system under intermittent solar irradiation using mixed integer linear programming. Energy and Buildings. 130: p. 253-271.

38. Ayodele, T.R., et al., Prioritized rule based load management technique for residential building powered by PV/battery system. Engineering Science and Technology, an International Journal. 20(3): p. 859-873.

39. Chouder, A., et al., Monitoring, modelling and simulation of PV systems using LabVIEW. Solar Energy. 91: p. 337-349.

40. Akinyele, D.O., R.K. Rayudu, and R.H.G. Tan, Comparative study of photovoltaic technologies based on performance, cost and space requirement: Strategy for selection and application. International Journal of Green Energy. 13(13): p. 13521368.

41. Fara, L. and D. Craciunescu, Output Analysis of Stand-alone PV Systems: Modeling, Simulation and Control. Energy Procedia. 112: p. 595-605.

42. Ferñ̃£o Pires, V., et al., A photovoltaic generator system with a DC/DC converter based on an integrated Boost- $\ddot{A} \nmid u k$ topology. Solar Energy. 136: p. 1-9.

43. Mashinchi Mahery, H. and E. Babaei, Mathematical modeling of buckâ€"boost $d c \hat{\epsilon} \epsilon$ "dc converter and investigation of converter elements on transient and steady state responses. International Journal of Electrical Power \& Energy Systems. 44(1): p. 949-963.

44. Sivakumar, S., et al., An assessment on performance of DCâ€"DC converters for renewable energy applications. Renewable and Sustainable Energy Reviews. 58: p. 1475-1485.

45. Mohapatra, A., et al., A review on MPPT techniques of PV system under partial shading condition. Renewable and Sustainable Energy Reviews. 80: p. 854-867.

46. Karami, N., N. Moubayed, and R. Outbib, General review and classification of different MPPT Techniques. Renewable and Sustainable Energy Reviews. 68: p. 1-18.

47. Eltawil, M.A. and Z. Zhao, MPPT techniques for photovoltaic applications. Renewable and Sustainable Energy Reviews. 25: p. 793-813.

48. Bounechba, H., et al., Real time simulation of MPPT algorithms for PV energy system. International Journal of Electrical Power \& Energy Systems. 83: p. 67-78.

49. Ou, T.-C. and C.-M. Hong, Dynamic operation and control of microgrid hybrid power systems. Energy. 66: p. 314-323.

50. Hong, C.-M., T.-C. Ou, and K.-H. Lu, Development of intelligent MPPT (maximum power point tracking) control for a grid-connected hybrid power generation system. Energy. 50: p. 270-279.

51. Shiau, J.-K., Y.-C. Wei, and M.-Y. Lee, Fuzzy Controller for a Voltage-Regulated Solar-Powered MPPT System for Hybrid Power System Applications. Energies. 8(5).

52. Hassan, Z.S., et al., Neuro-Fuzzy Wavelet Based Adaptive MPPT Algorithm for Photovoltaic Systems. Energies. 10(3).

53. Alik, R. and A. Jusoh, Modified Perturb and Observe $(P \& O)$ with checking algorithm under various solar irradiation. Solar Energy. 148: p. 128-139. 
54. Gosumbonggot, J., Maximum Power Point Tracking Method Using Perturb and Observe Algorithm for Small Scale DC Voltage Converter. Procedia Computer Science. 86: p. 421-424.

55. Ishaque, K., Z. Salam, and G. Lauss, The performance of perturb and observe and incremental conductance maximum power point tracking method under dynamic weather conditions. Applied Energy. 119: p. 228-236.

56. Putri, R.I., S. Wibowo, and M. Rifaâ€ ${ }^{\mathrm{TM}} \mathrm{i}$, Maximum Power Point Tracking for Photovoltaic Using Incremental Conductance Method. Energy Procedia. 68: p. 22-30.

57. Sheik Mohammed, S., D. Devaraj, and T.P. Imthias Ahamed, A novel hybrid Maximum Power Point Tracking Technique using Perturb \& Observe algorithm and Learning Automata for solar PV system. Energy. 112: p. 1096-1106.

58. Twaha, S., et al., Performance analysis of thermoelectric generator using $d c-d c$ converter with incremental conductance based maximum power point tracking. Energy for Sustainable Development. 37: p. 86-98.

59. Yang, Y. and F.P. Zhao, Adaptive Perturb and Observe MPPT Technique for GridConnected Photovoltaic Inverters. Procedia Engineering. 23: p. 468-473.

60. Akinyele, D., J. Belikov, and Y. Levron, Battery Storage Technologies for Electrical Applications: Impact in Stand-Alone Photovoltaic Systems. Energies. 10(11).

61. Ijumba, N.M. and J. Ross. Electrical energy audit and load management for low income consumers. in AFRICON, 1996., IEEE AFRICON 4th. 1996.

62. Monyei, C.G. and A.O. Adewumi, Demand Side Management potentials for mitigating energy poverty in South Africa. Energy Policy. 111: p. 298-311.

63. Photovoltaic Module Manufacturing Carbon Footprint [Online]. [cited 24-Aug2017]; Available from: http://www.solarinnova.net/images/stories/en/productos/fotovoltaica/modulos/manual /pdf/si-esf-m-carbon-footprint.pdf.

64. Does Battery Storage Help or Hurt the Environment? [Online]. [cited 24-Aug2017]; Available from: http://www.solarinnova.net/images/stories/en/productos/fotovoltaica/modulos/manual /pdf/si-esf-m-carbon-footprint.pdf.

65. Greenhouse Gases Equivalencies Calculator - Calculations and References [Online]. [cited 24-Aug-2017]; Available from: https://www.epa.gov/energy/greenhouse-gasesequivalencies-calculator-calculations-and-references. 


\section{LIST OF TABLES}

Table 1: Absolute poverty measure for selected Nigeria states [7]

\begin{tabular}{|c|c|c|c|}
\hline \multirow{2}{*}{ State } & & \multicolumn{2}{|c|}{ Poverty measure (\%) } \\
\cline { 3 - 4 } & Geo-political zone & $\mathbf{2 0 0 3 / 2 0 0 4}$ & $\mathbf{2 0 0 9 / 2 0 1 0}$ \\
\hline Lagos & South-west & 69.4 & 40.3 \\
\hline Abia & South-east & 40.9 & 50.2 \\
\hline Katsina & North-west & 72.9 & 77.6 \\
\hline Edo & South-south & 53.6 & 64.1 \\
\hline Kogi & North-central & 91.8 & 67.4 \\
\hline Borno & North-east & 59.8 & 60.6 \\
\hline
\end{tabular}

Table 2: Average monthly household expenditure (Naira) on gas, electricity, petrol and diesel by geo-political zone $[8,9]$

\begin{tabular}{|c|c|c|c|c|c|c|}
\hline & $\begin{array}{c}\text { North- } \\
\text { central }\end{array}$ & $\begin{array}{c}\text { North- } \\
\text { east }\end{array}$ & $\begin{array}{c}\text { North- } \\
\text { west }\end{array}$ & $\begin{array}{c}\text { South- } \\
\text { east }\end{array}$ & $\begin{array}{c}\text { South- } \\
\text { south }\end{array}$ & $\begin{array}{c}\text { South- } \\
\text { west }\end{array}$ \\
\hline Gas & 300 & 103 & 179 & 807 & 2890 & 617 \\
\hline Electricity & 5401 & 2216 & 2667 & 9972 & 8152 & 13105 \\
\hline Petrol & 14233 & 4688 & 10393 & 10895 & 18019 & 18516 \\
\hline Diesel & 597 & 351 & 436 & 787 & 538 & 2659 \\
\hline
\end{tabular}

Table 3: Frequency of blackouts across the geo-political zones [9]

\begin{tabular}{|c|c|c|c|}
\hline Region & Never & Everyday & Several times a week \\
\hline North-central & 3.3 & 63.5 & 26.6 \\
\hline North-ease & 1.5 & 71.3 & 23.6 \\
\hline North-west & 5.0 & 71.5 & 17.6 \\
\hline South-east & 1.4 & 60.2 & 29.1 \\
\hline South-south & 3.1 & 49.5 & 26.0 \\
\hline South-west & 4.4 & 49.0 & 41.2 \\
\hline
\end{tabular}


Table 4: Daily dispatch profile for considered loads

\begin{tabular}{|c|c|c|c|c|c|c|c|c|c|c|c|c|c|c|c|c|c|c|}
\hline \multirow{2}{*}{$\begin{array}{l}\text { Loa } \\
\mathrm{d} \\
\text { poin } \\
\mathrm{t}\end{array}$} & \multirow{2}{*}{$\begin{array}{l}\text { Uni } \\
\mathrm{t} \\
\text { (W } \\
\text { ) }\end{array}$} & \multicolumn{17}{|c|}{ Weekday time dispatch of load } \\
\hline & & 1 & 2 & 3 & 4 & 5 & 6 & 7 & 13 & 14 & 17 & 18 & 19 & 20 & 21 & 22 & 23 & 24 \\
\hline LP1 & 200 & 0 & 0 & 0 & 0 & 0 & 0 & 1 & 0 & 0 & 1 & 1 & 1 & 1 & 1 & 1 & 0 & 0 \\
\hline LP2 & 96 & 0 & 0 & 0 & 0 & 0 & 1 & 1 & 0 & 0 & 0 & 0 & 1 & 1 & 1 & 1 & 1 & 1 \\
\hline LP3 & 32 & 1 & 1 & 1 & 1 & 1 & 1 & 0 & 0 & 0 & 0 & 0 & 1 & 1 & 1 & 1 & 1 & 1 \\
\hline LP4 & 225 & 1 & 1 & 1 & 1 & 1 & 0 & 0 & 0 & 0 & 1 & 1 & 1 & 1 & 1 & 1 & 1 & 1 \\
\hline LP5 & 55 & $@$ & @ & $@$ & $@$ & @ & @ & @ & @ & @ & @ & @ & @ & @ & @ & @ & @ & @ \\
\hline LP6 & 75 & $\&$ & $\&$ & $\&$ & $\&$ & $\&$ & $\&$ & $\&$ & $\&$ & $\&$ & $\&$ & $\&$ & $\&$ & $\&$ & $\&$ & $\&$ & $\&$ & $\&$ \\
\hline 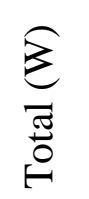 & & $\begin{array}{l}\infty \\
+ \\
8 \\
+ \\
+ \\
\text { in }\end{array}$ & 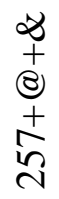 & 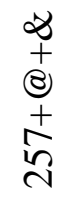 & 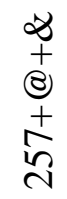 & 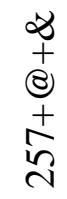 & $\begin{array}{l}\text { ષ } \\
+ \\
8 \\
+ \\
+ \\
\infty \\
\text { I }\end{array}$ & 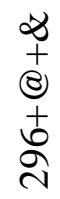 & $\begin{array}{l}\otimes \\
+ \\
\text { (8) }\end{array}$ & $\begin{array}{l}\infty \\
+ \\
\text { (8) }\end{array}$ & $\begin{array}{l}\infty \\
+ \\
\text { \&) } \\
+ \\
\text { f } \\
\text { f }\end{array}$ & 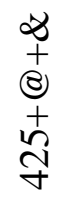 & $\begin{array}{l}\infty \\
+ \\
\text { \& } \\
+ \\
\infty \\
n \\
n\end{array}$ & $\begin{array}{l}\infty \\
+ \\
\text { \&) } \\
+ \\
\infty \\
n \\
n\end{array}$ & $\begin{array}{l}\infty \\
+ \\
\text { e) } \\
+ \\
\text { कn } \\
n \\
n\end{array}$ & 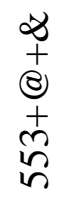 & $\begin{array}{l}\infty \\
+ \\
\text { \&) } \\
+ \\
m \\
n \\
n\end{array}$ & $\begin{array}{l}\infty \\
+ \\
\text { \&) } \\
+ \\
m \\
n \\
n\end{array}$ \\
\hline
\end{tabular}

1 - Valid period for load point dispatch

0 - Not a valid period for load point dispatch

@ - Fraction of others 1 dispatched

$\&$ - Fraction of others 2 dispatched

Table 5: Needs - Appliances Matrix

\begin{tabular}{|c|c|c|c|c|c|}
\hline & \multicolumn{4}{|c|}{ Needs } \\
\hline & & $\mathrm{N}-1$ & $\mathrm{~N}-2$ & $\mathrm{~N}-3$ & $\mathrm{~N}-4$ \\
\hline \multirow{6}{*}{ 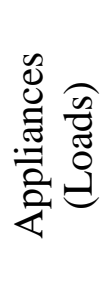 } & LP1 & $\mathrm{X}$ & $\mathrm{X}$ & $\mathrm{V}$ & $\mathrm{X}$ \\
\hline & LP2 & V & $X$ & $X$ & $X$ \\
\hline & LP3 & $\mathrm{V}$ & $X$ & $X$ & $X$ \\
\hline & LP4 & $\mathrm{X}$ & $\mathrm{V}$ & $\mathrm{X}$ & $X$ \\
\hline & LP5 & $X$ & $X$ & V & V \\
\hline & LP6 & $X$ & $X$ & $\mathrm{~V}$ & $\mathrm{~V}$ \\
\hline
\end{tabular}

$\mathrm{X}$ - Need cannot be met by appliance

$\mathrm{V}-$ Need can be met by appliance

$\mathrm{N}-1$ is Lighting need; $\mathrm{N}-2$ is Cooling need;

$\mathrm{N}-3$ is Entertainment need; N-4 is others

Table 6: Utility based associated statistics for LP1 - LP6

\begin{tabular}{|c|c|c|c|c|}
\hline \multirow{2}{*}{} & \multicolumn{4}{|c|}{ Needs } \\
\cline { 2 - 5 } & $\mathrm{N}-1$ & $\mathrm{~N}-2$ & $\mathrm{~N}-3$ & $\mathrm{~N}-4$ \\
\hline$H_{i, j}$ & $128 \mathrm{Wh}$ & $225 \mathrm{Wh}$ & $200 \mathrm{Wh}$ & $130 \mathrm{Wh}$ \\
\hline$C_{i, j}^{\text {utility }}$ & 2.73 Naira $(\$ 0.01)$ & 4.79 naira $(\$ 0.02)$ & 4.26 Naira $(\$ 0.01)$ & 2.77 Naira $(\$ 0.01)$ \\
\hline$C_{i, j}^{\text {Total-unmet }}$ & $40 \mathrm{Naira}(\$ 0.13)$ & $15 \mathrm{Naira}(\$ 0.05)$ & $5 \mathrm{Naira}(\$ 0.02)$ & 15 Naira $(\$ 0.05)$ \\
\hline$U_{i, j}^{\text {utility }}$ & 5.93 & 5.68 & 5.15 & 5.82 \\
\hline
\end{tabular}


Table 7: Petrol generator associated characteristics

\begin{tabular}{|c|c|}
\hline \multicolumn{2}{|c|}{ Generator Characteristics } \\
\hline Burn rate & 1.6 Litre/hour \\
\hline $\mathrm{CO}_{2}$ emissions per Litre & $2.392 \mathrm{kgCO}_{2} /$ Litre \\
\hline Hours of utilization per day & 6 \\
\hline Monthly maintenance cost & $\$ 4.92$ \\
\hline Petrol cost/Litre & $\$ 0.48$ \\
\hline
\end{tabular}

Table 8: Generator based associated statistics for LP1 - LP6

\begin{tabular}{|c|c|c|c|c|}
\hline & \multicolumn{4}{|c|}{ Needs } \\
\cline { 2 - 5 } & $\mathrm{N}-1$ & $\mathrm{~N}-2$ & $\mathrm{~N}-3$ & $\mathrm{~N}-4$ \\
\hline$H_{i, j}$ & $128 \mathrm{Wh}$ & $225 \mathrm{Wh}$ & $\$ 200 \mathrm{Wh}$ & $\$ 0.28$ \\
\hline$C_{i, j}^{\text {generator }}$ & $\$ 0.28$ & $\$ 0.49$ & $\$ 0.43$ & $\$ 0.05$ \\
\hline$C_{i, j}^{\text {unmet }}$ & $\$ 0.13$ & $\$ 0.05$ & $\$ 0.02$ & 0.28 \\
\hline$U_{i, j}^{\text {generator }}$ & 3.89 & -3.90 & -20.41 & \\
\hline
\end{tabular}

Table 9: Comfort cost breakdown for each sub load point and Need

\begin{tabular}{|c|c|c|c|c|c|c|c|c|c|c|c|c|c|c|c|c|c|}
\hline Needs & \multicolumn{8}{|c|}{$\mathrm{N}-1$} & \multicolumn{3}{|c|}{$\mathrm{N}-2$} & $\mathrm{~N}-3$ & \multicolumn{5}{|c|}{$\mathrm{N}-4$} \\
\hline Load points & 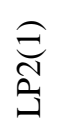 & 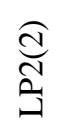 & 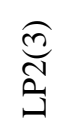 & 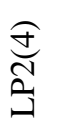 & 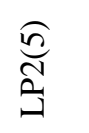 & $\underset{\mathbb{N}}{\stackrel{6}{\Delta}}$ & 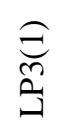 & $\begin{array}{l}\text { త్ } \\
\stackrel{\Xi}{a}\end{array}$ & 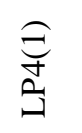 & $\begin{array}{l}\overparen{d} \\
\stackrel{+}{a}\end{array}$ & $\begin{array}{c}\widehat{(S)} \\
\stackrel{+}{ \pm}\end{array}$ & $\bar{a}$ & $\widehat{\overparen{\varpi}}$ & $\begin{array}{l}\overparen{d} \\
\stackrel{d}{a}\end{array}$ & $\stackrel{\widehat{c}}{\varkappa}$ & $\begin{array}{l}\overparen{\Xi} \\
\stackrel{\Xi}{ప}\end{array}$ & $\begin{array}{l}\text { త్ర } \\
\stackrel{\text { ప }}{1}\end{array}$ \\
\hline $\begin{array}{l}\text { Comfort } \\
\text { cost }(\$)\end{array}$ & 0.02 & 0.02 & 0.02 & 0.02 & 0.02 & 0.02 & 0.02 & 0.02 & 0.02 & 0.02 & 0.02 & 0.02 & 0.01 & 0.01 & 0.01 & 0.01 & 0.01 \\
\hline$C_{i, j}^{\text {Total-unmet }}$ & \multicolumn{8}{|c|}{0.13} & \multicolumn{3}{|c|}{0.05} & 0.02 & \multicolumn{5}{|c|}{0.05} \\
\hline
\end{tabular}

Table 10: Associated parameters for PV panel, converter, battery and inverter

\begin{tabular}{|c|c|c|c|c|c|c|c|}
\hline \multicolumn{2}{|c|}{ PV panel } & \multicolumn{2}{c|}{ Converter } & \multicolumn{2}{c|}{ Battery } & \multicolumn{2}{c|}{ Inverter } \\
\hline Number & 2 & $r_{i}$ & $5 m \Omega$ & Voltage & $24 \mathrm{~V}$ & $\eta_{\text {inv }}$ & 0.9 \\
\hline Power & $80 \mathrm{Wp}$ & $r_{L}$ & $0.2 \Omega$ & Rating & $100 \mathrm{Ah}$ & Rating & $1 \mathrm{kVA}$ \\
\hline$\eta_{P V}$ & $16 \%$ & $R_{L}$ & $15 \Omega$ & $\eta_{\text {batt }}$ & 0.9 & & \\
\hline Cost & $\$ 188.12$ & $F_{s}$ & $5000 H z$ & DOD & $90 \%$ & & \\
\hline Life cycle & 25 years & $k$ & 0.5 & $\sigma$ & $<3 \% /$ month & & \\
\hline$V_{m p}$ & $18 \mathrm{~V}$ & $C_{i}$ & $200 \mu F$ & Life cycle & 3 years & & \\
\hline$I_{m p}$ & $4.44 \mathrm{~A}$ & $C_{o}$ & $333.33 \mu F$ & Cost & $\$ 200$ & & \\
\hline Weight & $7.4 \mathrm{~kg}$ & $L$ & $18.75 m H$ & & & & \\
\hline
\end{tabular}


Table 11: Initial purchase, installation and daily operations cost for considered generation sources

\begin{tabular}{|c|c|c|c|c|}
\hline \multirow{4}{*}{$\begin{array}{l}\tilde{n} \\
\dot{0} \\
\dot{0}\end{array}$} & & \multicolumn{3}{|c|}{ Generation sources } \\
\hline & & PV/battery & Utility & Generator \\
\hline & Initial purchase & $\$ 486.49^{*}$ & $\$ 163.93^{++}$ & $\$ 574^{*}$ \\
\hline & Maintenance & $\$ 8.20 /$ year & No maintenance fee & \$4.92/month \\
\hline & Hourly operations & $\$ 0^{\#}$ & $\$ 0.07 \times D_{\text {hour }}^{k}(k W h)$ & $\$ 0.09^{\#}$ \\
\hline
\end{tabular}

*- Inclusive of installation cost

++ - Households were initially charged for pre-paid meters with a payment plan spread across 12 months.

\# - Charge is flat for the hour as long as demand can be met by available generation capacity.

$D_{i}(k W h)$ is the hourly demand to be dispatched by the PV/battery.

Table 12: Load audit of use case low-cost house

\begin{tabular}{|c|c|c|c|c|}
\hline Device & Code & Number & Unit rating (W) & Total power (W) \\
\hline Television $^{*}$ & LP1 & 1 & 200 & 200 \\
\hline Indoor light $^{*}$ & LP2 & 6 & 16 & 96 \\
\hline Outdoor light $^{*}$ & LP3 & 2 & 16 & 32 \\
\hline Standing/ceiling fan $^{*}$ & LP4 & 3 & 75 & 225 \\
\hline Others 1 & LP5 & - & 55 & 55 \\
\hline Others 2 & LP6 & - & 75 & 75 \\
\hline Electric cooker, $^{+* *}$ & - & 1 & 1500 & 1500 \\
\hline Fridge/Freezer $^{+, * *}$ & - & 1 & 400 & 400 \\
\hline Electric kettle+,** $^{+*}$ & - & 1 & 1000 & 1000 \\
\hline Pressing iron $^{+* *}$ & - & 1 & 1000 & 1000 \\
\hline Total & & & & 4583 \\
\hline
\end{tabular}

* Class one load points

** - Class two load points

+ Not considered for alternative power supply

Table 13: Power rating of others 1 and others 2 sub-load points

\begin{tabular}{|l|l|l|l|l|l|}
\hline $\begin{array}{l}\text { Class } \\
\text { definition }\end{array}$ & Class constituent & Number & Description & $\begin{array}{l}\text { Unit rating } \\
(\mathrm{W})\end{array}$ & Total power (W) \\
\hline \multirow{3}{*}{ Others 1} & Satellite decoder & 1 & LP5(1) & 10 & 10 \\
\cline { 2 - 6 } & Phone charger & 2 & LP5(2) & 10 & 20 \\
\cline { 2 - 6 } & DVD player & 1 & LP5(3) & 25 & 25 \\
\hline \multirow{2}{*}{ Others 2 } & Laptop & 1 & LP6(1) & 65 & 65 \\
\cline { 2 - 6 } & Bedside light & 1 & LP6(2) & 10 & 10 \\
\hline
\end{tabular}


Table 14: Demand schedule for hours under consideration

\begin{tabular}{|c|c|c|c|c|c|c|c|c|c|c|c|c|c|c|c|c|c|}
\hline & \multirow[b]{2}{*}{$\bar{a}$} & \multicolumn{6}{|c|}{ LP2 } & \multicolumn{2}{|c|}{ LP3 } & \multicolumn{3}{|c|}{ LP4 } & \multicolumn{3}{|c|}{ LP5 } & \multicolumn{2}{|c|}{ LP6 } \\
\hline & & 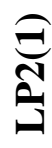 & 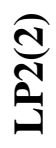 & 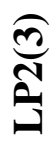 & 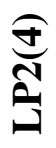 & $\frac{\sqrt{n}}{\mathbb{N}}$ & 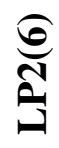 & 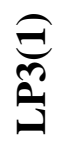 & త్రి & 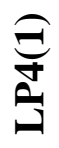 & $\begin{array}{l}\overparen{\Xi} \\
\stackrel{+}{\Xi}\end{array}$ & $\frac{\widehat{9}}{\stackrel{9}{a}}$ & 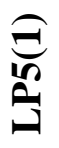 & $\frac{\overparen{d}}{\stackrel{d}{d}}$ & $\frac{\mathfrak{n}}{n ! n}$ & ڤ్రై & 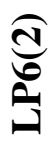 \\
\hline 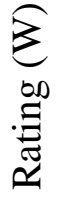 & ঠ্ণ & $\underset{1}{0}$ & $\stackrel{0}{0}$ & $\underline{\sigma}$ & $\underline{\sigma}$ & $\underline{0}$ & $\underline{\sigma}$ & $\underline{\sigma}$ & $\underline{0}$ & $\stackrel{n}{n}$ & $n$ & $n$ & $\stackrel{0}{0}$ & 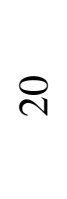 & $\approx$ & 6 & $\stackrel{0}{=}$ \\
\hline 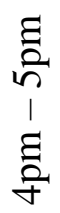 & V & & & & & & & & & & V & & V & V & V & & V \\
\hline 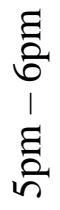 & V & & & & & & & & & V & & V & V & & V & & \\
\hline 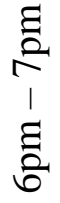 & & & & & & V & V & V & V & V & V & V & V & V & V & V & \\
\hline 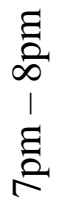 & V & V & V & V & V & & & & & & & & & & & & \\
\hline
\end{tabular}

Table 15: Daily needs computation and dispatch schedule

\begin{tabular}{|c|c|c|c|c|}
\hline \multirow{2}{*}{ Needs } & \multicolumn{4}{|c|}{ Time span under consideration } \\
\cline { 2 - 5 } & $4 \mathrm{pm}-5 \mathrm{pm}$ & $5 \mathrm{pm}-6 \mathrm{pm}$ & $6 \mathrm{pm}-7 \mathrm{pm}$ & $7 \mathrm{pm}-8 \mathrm{pm}$ \\
\hline $\mathrm{N}-1$ & $0 / 0 \mathrm{Wh}$ & $0 / 0 \mathrm{Wh}$ & $64 / 41.37 \mathrm{Wh}$ & $96 / 0 \mathrm{Wh}$ \\
\hline $\mathrm{N}-2$ & $75 / 75 \mathrm{Wh}$ & $150 / 150 \mathrm{Wh}$ & $225 / 0 \mathrm{Wh}$ & $75 / 0 \mathrm{Wh}$ \\
\hline $\mathrm{N}-3$ & $200 / 200 \mathrm{Wh}$ & $200 / 200 \mathrm{Wh}$ & $0 / 0 \mathrm{Wh}$ & $200 / 0 \mathrm{Wh}$ \\
\hline $\mathrm{N}-4$ & $65 / 65 \mathrm{Wh}$ & $35 / 30.30 \mathrm{Wh}$ & $120 / 0 \mathrm{Wh}$ & $25 / 0 \mathrm{Wh}$ \\
\hline \multirow{2}{*}{ Notes } & $\begin{array}{c}\text { PV+battery only } \\
\text { Utility available }\end{array}$ & $\begin{array}{c}\text { PV+battery+utility } \\
\text { Utility available }\end{array}$ & $\begin{array}{c}\text { PV+battery+utility } \\
\text { Utility available }\end{array}$ & $\begin{array}{c}\text { No PV+battery } \\
\text { Utility unavailable }\end{array}$ \\
\hline
\end{tabular}

64/41.37 Wh represents $64 \mathrm{Wh}$ demanded and $41.37 \mathrm{Wh}$ supplied by PV/battery. The deficit is met by the utility (grid) if available. 
Table 16: Daily computation of $U_{i, j}^{P V / b a t t e r y}, C_{i, j}^{\text {unmet }}$ and savings (nominal)

\begin{tabular}{|c|c|c|c|c|c|c|c|c|}
\hline & \multicolumn{4}{|c|}{ Needs for $4 \mathrm{pm}-5 \mathrm{pm}$} & \multicolumn{4}{|c|}{ Needs for $6 \mathrm{pm}-7 \mathrm{pm}$} \\
\hline & N-1 & N-2 & N-3 & $\mathrm{N}-4$ & $\mathrm{~N}-1$ & N-2 & N-3 & $\mathrm{N}-4$ \\
\hline$H_{i, j}$ & $0 \mathrm{Wh}$ & $75 \mathrm{Wh}$ & $200 \mathrm{Wh}$ & $65 \mathrm{Wh}$ & $64 \mathrm{Wh}$ & $225 \mathrm{Wh}$ & $0 \mathrm{Wh}$ & $120 \mathrm{Wh}$ \\
\hline$U_{i, j}^{P V / b a t t e r y}$ & - & 5.31 & 5.94 & 5.78 & 5.24 & 4.98 & - & 4.98 \\
\hline$C_{i, j}^{\text {unmet }}$ (Naira) & - & $\begin{array}{c}0.00 \\
(\$ 0.00)\end{array}$ & $\begin{array}{c}0.00 \\
(\$ 0.00)\end{array}$ & $\begin{array}{c}0.00 \\
(\$ 0.00) \\
\end{array}$ & $\begin{array}{c}10.00 \\
(\$ 0.03)\end{array}$ & $\begin{array}{c}15.00 \\
(\$ 0.05)\end{array}$ & - & $\begin{array}{c}12.00 \\
(\$ 0.04)\end{array}$ \\
\hline \multirow[t]{3}{*}{ Savings (Naira) } & $\begin{array}{c}0.00 \\
(\$ 0.00)\end{array}$ & $\begin{array}{c}1.6 \\
(\$ 0.01)\end{array}$ & $\begin{array}{c}4.26 \\
(\$ 0.01)\end{array}$ & $\begin{array}{c}1.38 \\
(\$ 0.00)\end{array}$ & $\begin{array}{c}0.88 \\
(\$ 0.00)\end{array}$ & $\begin{array}{c}0.00 \\
(\$ 0.00)\end{array}$ & - & $\begin{array}{c}0.00 \\
(\$ 0.00)\end{array}$ \\
\hline & \multicolumn{4}{|c|}{ Needs for $5 \mathrm{pm}-6 \mathrm{pm}$} & \multicolumn{4}{|c|}{ Needs for $7 \mathrm{pm}-8 \mathrm{pm}$} \\
\hline & N-1 & N-2 & N-3 & $\mathrm{N}-4$ & $\mathrm{~N}-1$ & $\mathrm{~N}-2$ & N-3 & $\mathrm{N}-4$ \\
\hline$H_{i, j}$ & $0 \mathrm{Wh}$ & $150 \mathrm{Wh}$ & $200 \mathrm{Wh}$ & $35 \mathrm{Wh}$ & $96 \mathrm{Wh}$ & $75 \mathrm{Wh}$ & $200 \mathrm{Wh}$ & $25 \mathrm{Wh}$ \\
\hline$U_{i, j}^{P V / b a t t e r y}$ & - & 5.65 & 5.94 & 5.14 & 4.99 & 4.98 & 4.94 & 4.98 \\
\hline$C_{i, j}^{\text {unmet }}$ (Naira) & - & $\begin{array}{c}0.00 \\
(\$ 0.00)\end{array}$ & $\begin{array}{c}0.00 \\
(\$ 0.00)\end{array}$ & $\begin{array}{c}3.00 \\
(\$ 0.01)\end{array}$ & 30 & 5 & 5 & 3 \\
\hline Savings (Naira) & $\begin{array}{c}0.00 \\
(\$ 0.00)\end{array}$ & $\begin{array}{c}3.20 \\
(\$ 0.01)\end{array}$ & $\begin{array}{c}4.26 \\
(\$ 0.01)\end{array}$ & $\begin{array}{c}0.65 \\
(\$ 0.00)\end{array}$ & $\begin{array}{c}0.00 \\
(\$ 0.00)\end{array}$ & $\begin{array}{c}0.00 \\
(\$ 0.01)\end{array}$ & $\begin{array}{c}0.00 \\
(\$ 0.00)\end{array}$ & $\begin{array}{c}0.00 \\
(\$ 0.00)\end{array}$ \\
\hline
\end{tabular}

Table 17: Daily, monthly and yearly effective demand cost for the different options

\begin{tabular}{|l|c|c|c|}
\hline & Daily & Monthly & Yearly \\
\hline Effective demand $(\mathrm{kWh})$ & 2.27 & 69.02 & 828.19 \\
\hline Utility only cost (Naira) & $48.12(\$ 0.16)$ & $1470(\$ 4.82)$ & $17640(\$ 57.84)$ \\
\hline PV/battery/utility cost (Naira) & $31.89(\$ 0.10)$ & $976(\$ 3.20)$ & $11716(\$ 38.41)$ \\
\hline \multirow{3}{*}{ Utility/generator cost (Naira) } & Utility (48.12 Naira, \$0.16) & $1470(\$ 4.82)$ & $17640(\$ 57.84)$ \\
& Generator (3150 Naira, $\$ 10.33)$ & $95813(\$ 314)$ & $1149750(\$ 3770)$ \\
\cline { 2 - 4 } & $3198.12(\$ 10.49)$ & $97283(\$ 319)$ & $1167390(\$ 3828)$ \\
\hline
\end{tabular}

Table 18: Carbon emissions for PV, battery, utility and generator

\begin{tabular}{|c|c|}
\hline Component & Emission rate \\
\hline PV & $72 \mathrm{gCO}_{2} \mathrm{e} / \mathrm{kWh}^{+,} @$ \\
\hline Battery & $50 \mathrm{gCO}_{2} / \mathrm{kWh}^{++}$ \\
\hline Utility & $0.703 \mathrm{kgCO}_{2} / \mathrm{kWh}^{*}$ \\
\hline Generator & $3.827 \mathrm{kgCO}_{2} /$ hour $^{\#}$ \\
\hline \multicolumn{2}{|c|}{$\begin{array}{l}+ \text { - see }[63] ;++- \text { see }[64] ; \\
\text { * - see }[65] ; \# \text { - Computed in this paper } \\
@ \text { - has been taken to be } \mathrm{CO}_{2} / \mathrm{kWh}\end{array}$} \\
\hline
\end{tabular}


Table 19: Daily carbon emissions from the various sources

\begin{tabular}{|c|c|}
\hline Electricity source & \multicolumn{1}{|c|}{ Daily emission } \\
\hline Grid only & $1.588 \mathrm{kgCO}_{2}{ }^{*}$ \\
\hline $\mathrm{PV} /$ battery/utility & $\begin{array}{l}\mathrm{PV}-0.104 \mathrm{kgCO}_{2} \\
\text { Battery }-0.023 \mathrm{kgCO}_{2} \\
\text { Utility }-1.052 \mathrm{kgCO}_{2}{ }^{* *}\end{array}$ \\
\cline { 2 - 2 } & $1.179 \mathrm{kgCO}_{2}$ \\
\hline Utility/generator & $\begin{array}{l}\text { Utility }-1.588 \mathrm{kgCO}_{2}{ }^{*} \\
\text { Generator }-26.789 \mathrm{kgCO}_{2}\end{array}$ \\
\cline { 2 - 2 } & $28.384 \mathrm{kgCO}_{2}$ \\
\hline
\end{tabular}

*- Utility supply is $2259 \mathrm{Wh}$

**- Utility supply is $1496.60 \mathrm{Wh}$

Table 20: Summary of associated statistics for Utility, PV/battery/utility and Utility/generator configurations

\begin{tabular}{|c|c|c|c|c|c|c|c|}
\hline Time & Demand & \multicolumn{2}{|c|}{ Utility only } & \multicolumn{2}{|c|}{ PV/battery/utility } & \multicolumn{2}{|c|}{ Utility/generator } \\
\hline \multirow{4}{*}{$\begin{array}{c}4 \mathrm{pm} \\
- \\
5 \mathrm{pm}\end{array}$} & \multirow{4}{*}{\begin{tabular}{l}
\multirow{3}{3}{} \\
ơ \\
m
\end{tabular}} & $C_{i, j}^{\text {utility }}$ & $\begin{array}{c}7.24 \\
\text { Naira }\end{array}$ & $C_{i, j}^{P V / b a t t e r y / u t i l i t y}$ & 0.29 Naira & $C_{i, j}^{\text {utility/generator }}$ & $\begin{array}{c}7.24 \\
\text { Naira }\end{array}$ \\
\hline & & $U_{\text {avg }}^{\text {utility }}$ & 5.32 & $U_{\text {avg }}^{P V / b a t t e r y / u t i l i t y}$ & 5.68 & $U_{\text {avg }}^{\text {utility/generator }}$ & 5.32 \\
\hline & & \multirow[t]{2}{*}{ Status } & \multirow[t]{2}{*}{ Available } & PV/battery & Sufficient & Utility & V \\
\hline & & & & Grid & Available & Generator & $\mathrm{VX}$ \\
\hline \multirow{4}{*}{$\begin{array}{c}5 \mathrm{pm} \\
- \\
6 \mathrm{pm}\end{array}$} & \multirow{4}{*}{$\begin{array}{l}\frac{1}{3} \\
\infty \\
\infty \\
n\end{array}$} & $C_{i, j}^{\text {utility }}$ & $\begin{array}{c}8.20 \\
\text { Naira }\end{array}$ & $C_{i, j}^{P V / b a t t e r y / u t i l i t y}$ & 0.39 Naira & $C_{i, j}^{\text {utility/generator }}$ & $\begin{array}{c}8.20 \\
\text { Naira }\end{array}$ \\
\hline & & $U_{\text {avg }}^{\text {utility }}$ & 5.32 & $U_{\text {avg }}^{P V / b a t t e r y / u t i l i t y}$ & 5.58 & $U_{\text {avg }}^{\text {utility/generator }}$ & 5.32 \\
\hline & & \multirow[t]{2}{*}{ Status } & \multirow[t]{2}{*}{ Available } & PV/battery & Insufficient & Utility & $\mathrm{V}$ \\
\hline & & & & Grid & Available & Generator & VX \\
\hline \multirow{4}{*}{$\begin{array}{c}6 \mathrm{pm} \\
- \\
7 \mathrm{pm}\end{array}$} & \multirow{4}{*}{$\begin{array}{l}\frac{1}{3} \\
8 \\
\text { }\end{array}$} & $C_{i, j}^{u t i l i t y}$ & $\begin{array}{c}8.71 \\
\text { Naira }\end{array}$ & $C_{i, j}^{P V / b a t t e r y / u t i l i t y}$ & 8.12 Naira & $C_{i, j}^{\text {utility/generator }}$ & $\begin{array}{c}8.71 \\
\text { Naira }\end{array}$ \\
\hline & & $U_{\text {avg }}^{\text {utility }}$ & 5.59 & $U_{\text {avg }}^{P V / \text { battery/utility }}$ & 5.07 & $U_{\text {avg }}^{\text {utility/generator }}$ & 5.59 \\
\hline & & \multirow[t]{2}{*}{ Status } & \multirow[t]{2}{*}{ Available } & PV/battery & Insufficient & Utility & $\mathrm{V}$ \\
\hline & & & & Grid & Available & Generator & VX \\
\hline \multirow{4}{*}{$\begin{array}{c}7 \mathrm{pm} \\
- \\
8 \mathrm{pm}\end{array}$} & \multirow{4}{*}{$\begin{array}{l}\sum_{3}^{2} \\
\text { ळे }\end{array}$} & $C_{i, j}^{\text {utility }}$ & $\begin{array}{c}8.43 \\
\text { Naira }\end{array}$ & $C_{i, j}^{P V / b a t t e r y / u t i l i t y}$ & $\begin{array}{c}0.29 \\
\text { Naira }^{* * * *}\end{array}$ & $C_{i, j}^{\text {utility/generator }}$ & $\begin{array}{c}450 \\
\text { Naira }\end{array}$ \\
\hline & & $U_{\text {avg }}^{\text {utility }}$ & 4.24 & $U_{\text {avg }}^{P V / \text { battery/utility }}$ & 4.97 & $U_{\text {avg }}^{\text {utility/generator }}$ & -8.48 \\
\hline & & \multirow[t]{2}{*}{ Status } & \multirow{2}{*}{$\begin{array}{c}\text { Not } \\
\text { available }\end{array}$} & PV/battery & Insufficient & Utility & $\mathrm{X}$ \\
\hline & & & & Grid & Unavailable & Generator & VV \\
\hline
\end{tabular}

$\mathrm{V}$ - utilized in dispatching hourly needs; $\mathrm{X}$ - Source not available for dispatching needs

VX - Source available but not utilized in dispatching needs

VV - Source available and utilized in dispatching needs

*** - PV/battery normal hourly cost of electricity is assumed 
Table 21: Sensitivity analysis results for varying $E_{P C}($ Naira / $k W h)$

\begin{tabular}{|c|c|c|c|c|c|}
\hline \multirow{2}{*}{$\begin{array}{l}E_{P C} \\
(\text { Naira } / \mathrm{kWh})\end{array}$} & Unnual electricity cost (Naira) & Yearly savings & $\begin{array}{c}\text { Payback } \\
\text { period } \\
\text { (Naira) }\end{array}$ & $\begin{array}{c}\text { Annual } \\
\text { electricity cost } \\
\text { savings }(\%)\end{array}$ \\
\hline 21.30 & $17640(\$ 57.84)$ & $11716(\$ 38.41)$ & $5924(\$ 19.42)$ & 25 & 34 \\
\hline 25.00 & $13957(\$ 45.76)$ & $6715(\$ 22.02)$ & $7242(\$ 23.75)$ & 21 & 52 \\
\hline 30.00 & $16749(\$ 54.91)$ & $7395(\$ 24.24)$ & $9354(\$ 30.67)$ & 16 & 56 \\
\hline 50.00 & $27915(\$ 91.52)$ & $10112(\$ 33.16)$ & $17802(\$ 58.37)$ & 8.4 & 64 \\
\hline
\end{tabular}




\section{LIST OF FIGURES}

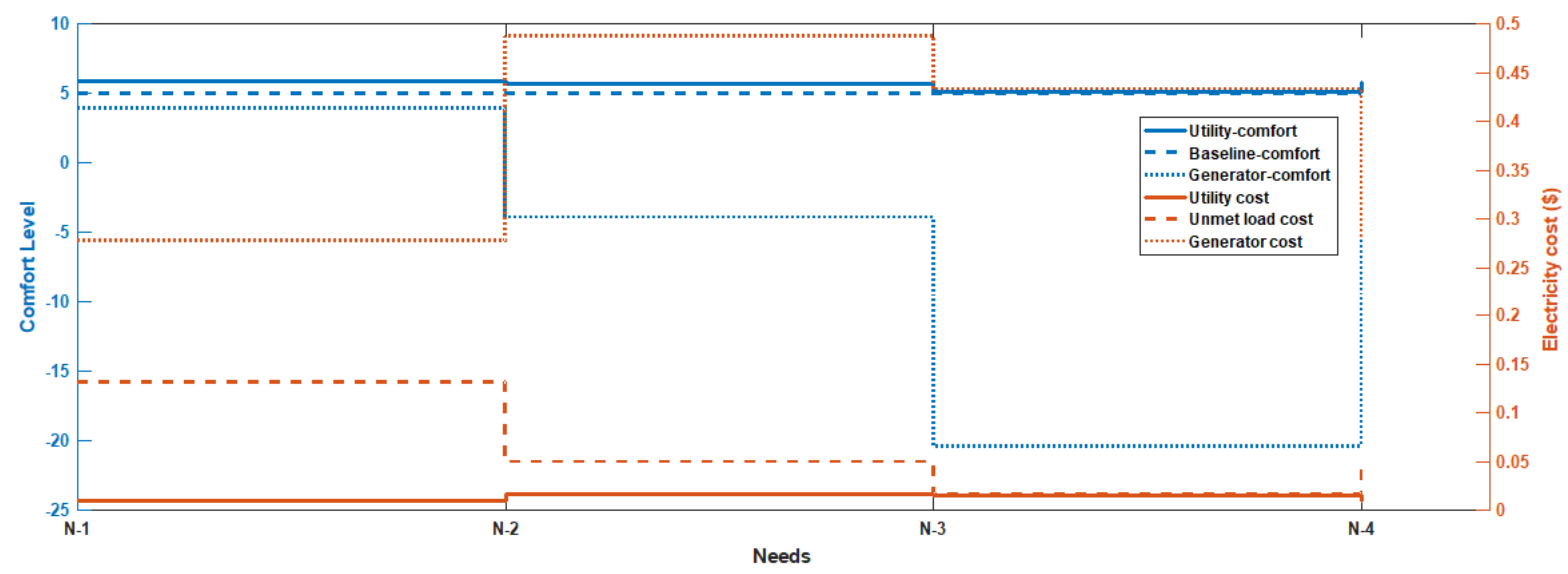

Figure 1: The combined comfort and expenditure plot for utility and generator

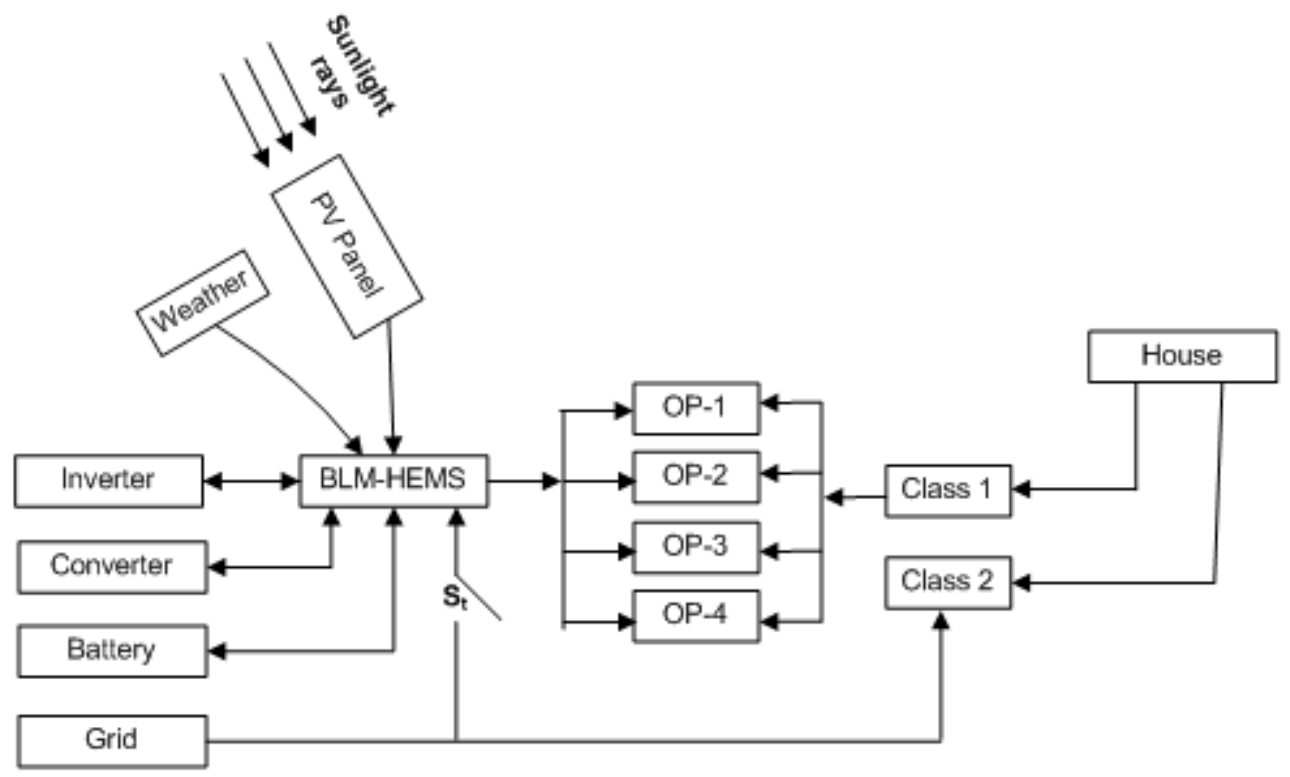

Figure 2: Proposed alternative system

"OP" in figure 2 means option, which represents a sub-collection of electrical appliances. 


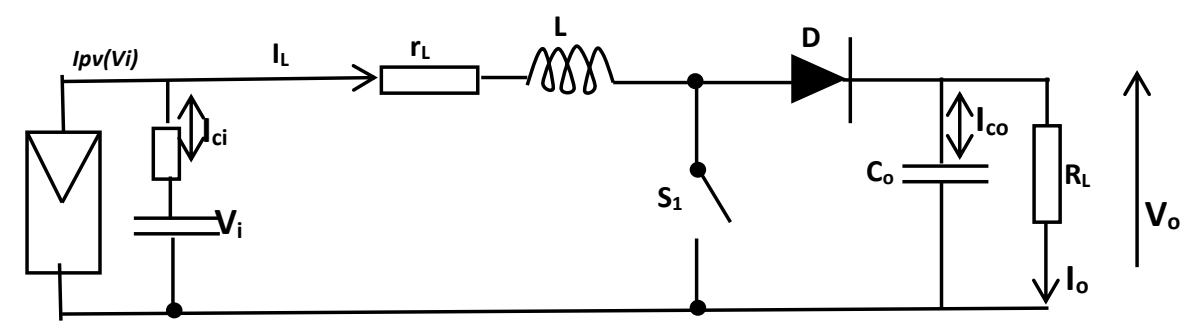

Figure 3: PV/DC-DC Boost-Converter Model

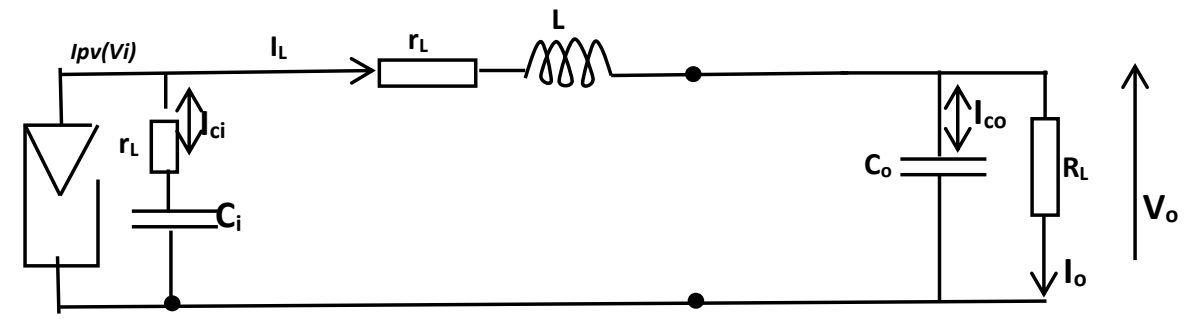

Figure 4: PV/DC-DC Boost-Converter Model for "OFF" state operation

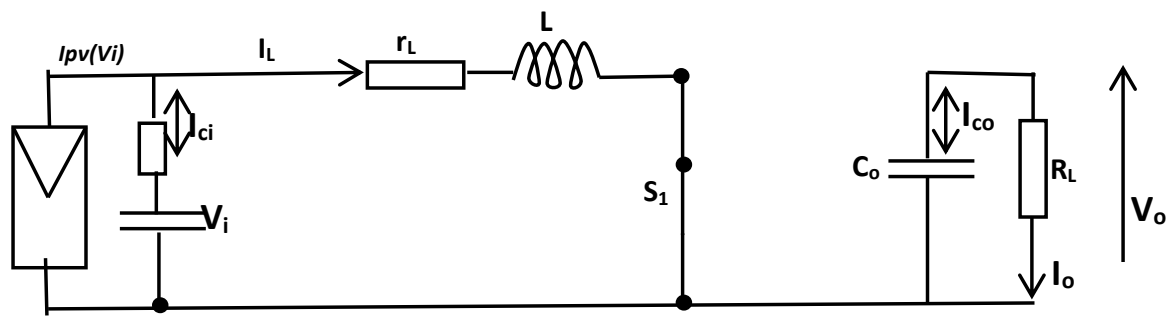

Figure 5: The PV/DC-DC Boost-Converter Model during the "ON" state

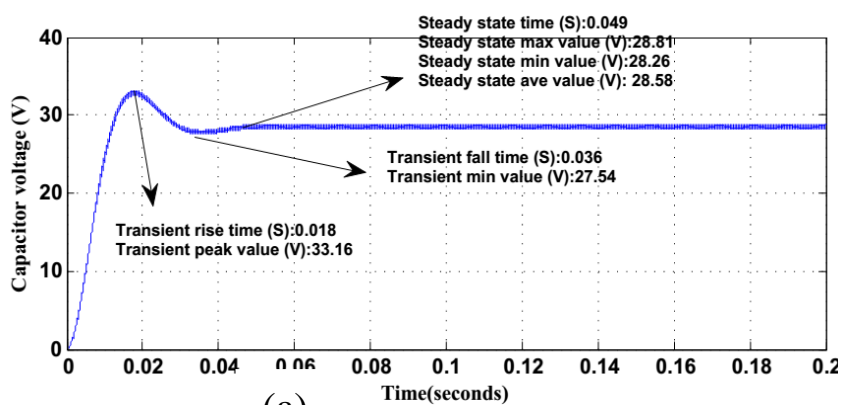

(a)

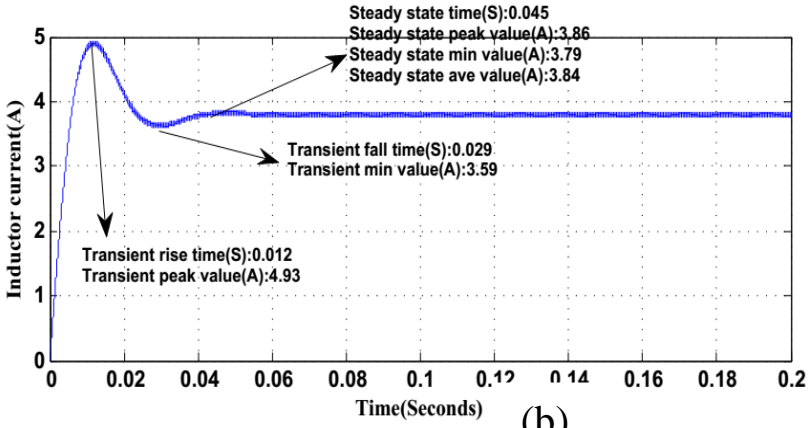

(b)

Figure 6: Transient and steady state response for (a) Capacitor voltage and (b) Inductor current 


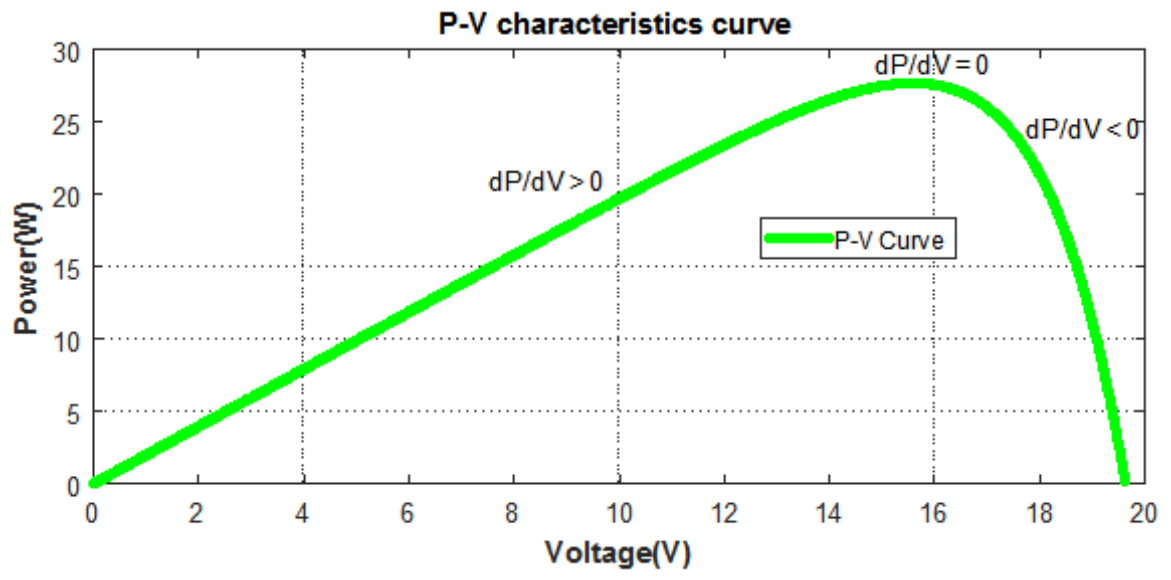

Figure 7: $\frac{d P}{d V}$ monitoring across the $\mathbf{P}-\mathrm{V}$ profile

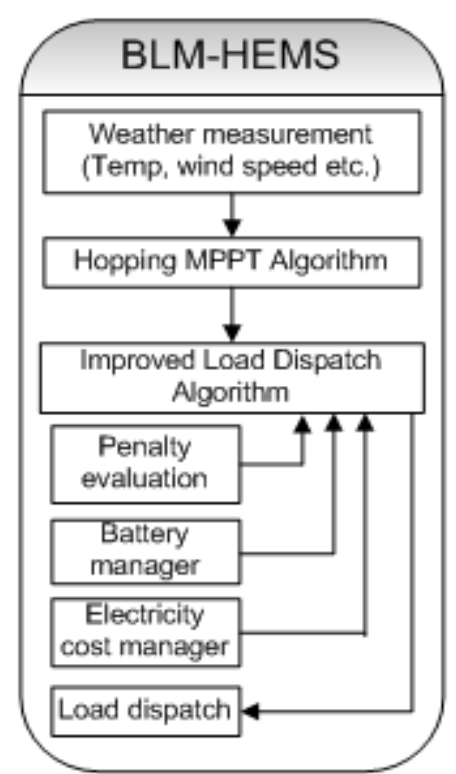

Figure 8: BLM-HEMS internal working architecture 


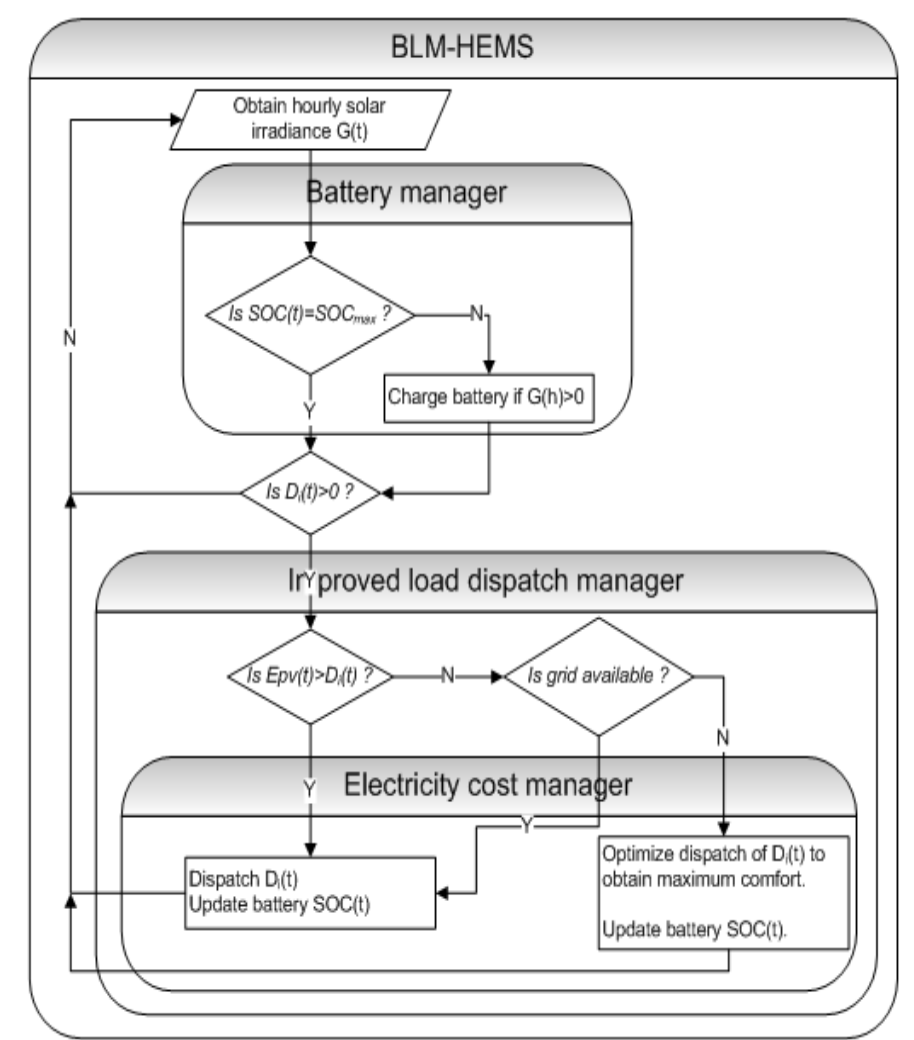

Figure 9: The BLM-HEMS flow chart

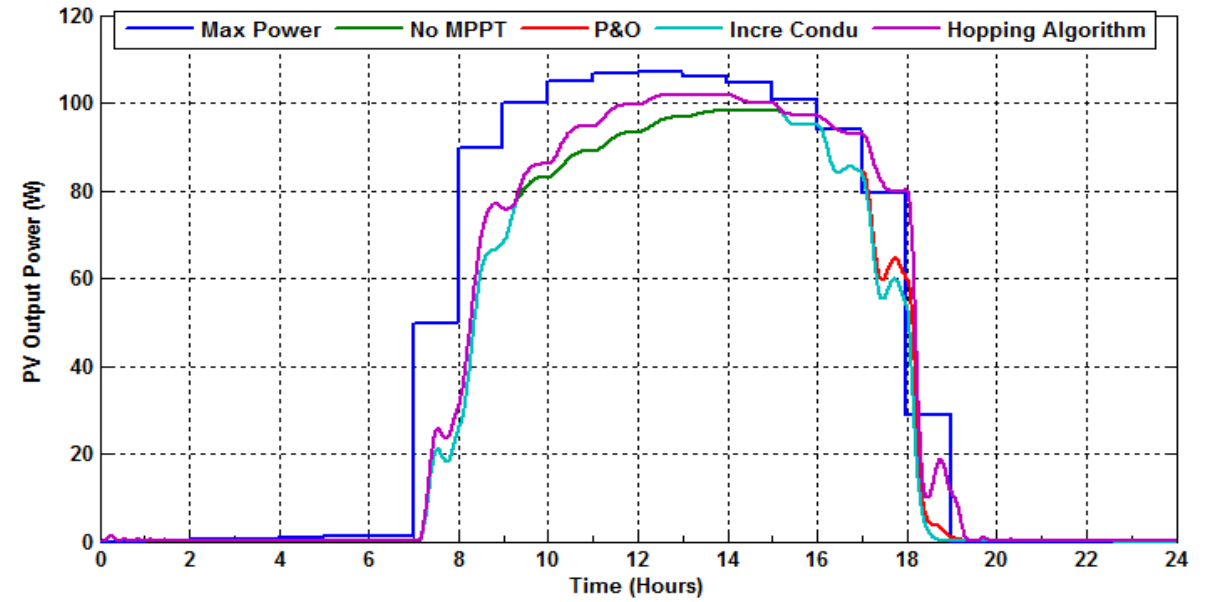

Figure 10: The daily MPPT tracking of the various methods employed 


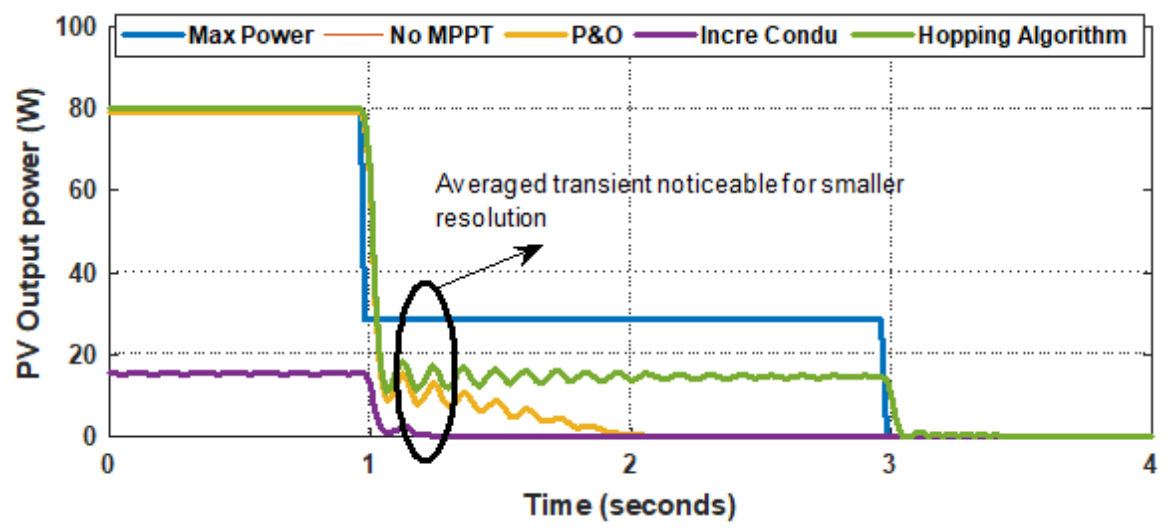

Figure 11: Transient behaviour of the various methods for smaller resolution

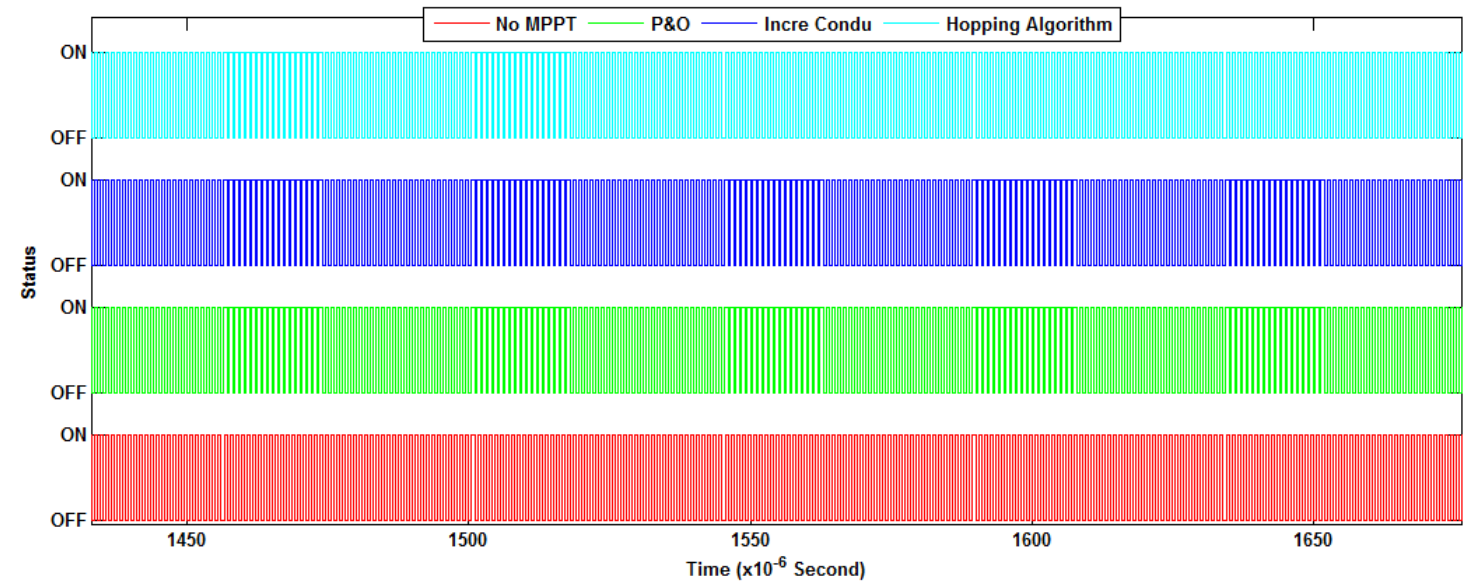

Figure 12: Snippet of the firing sequence of the converter for the various MPPT algorithms

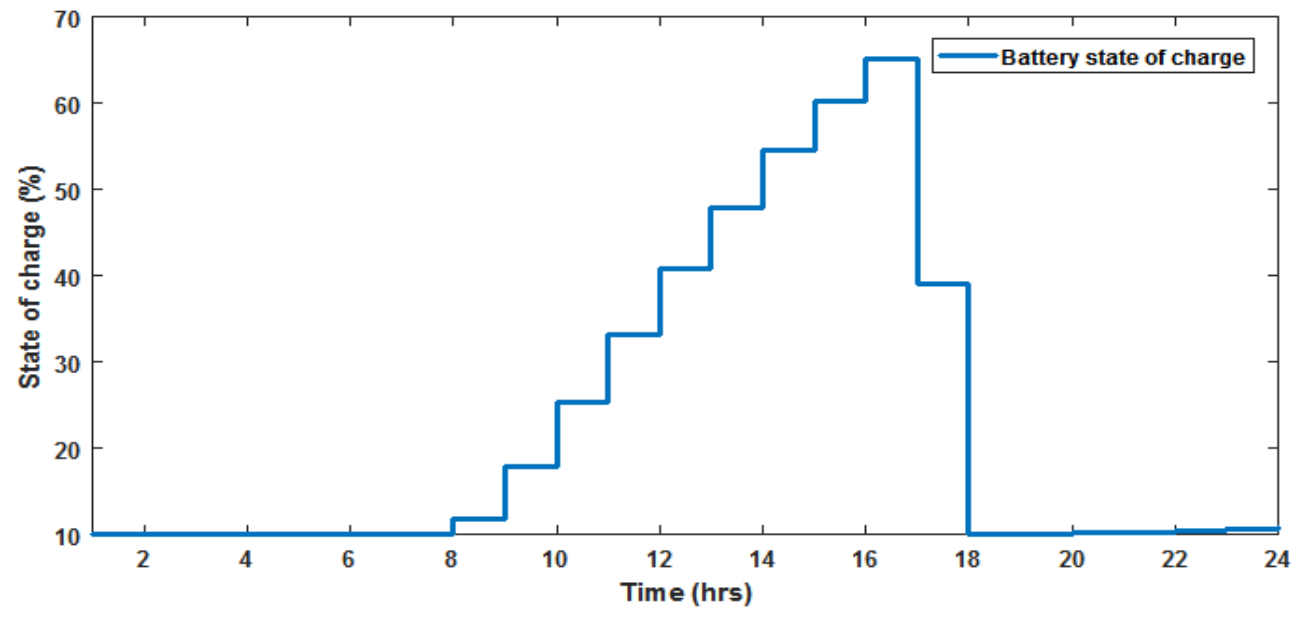

Figure 13: Battery daily state of charge during dry season 


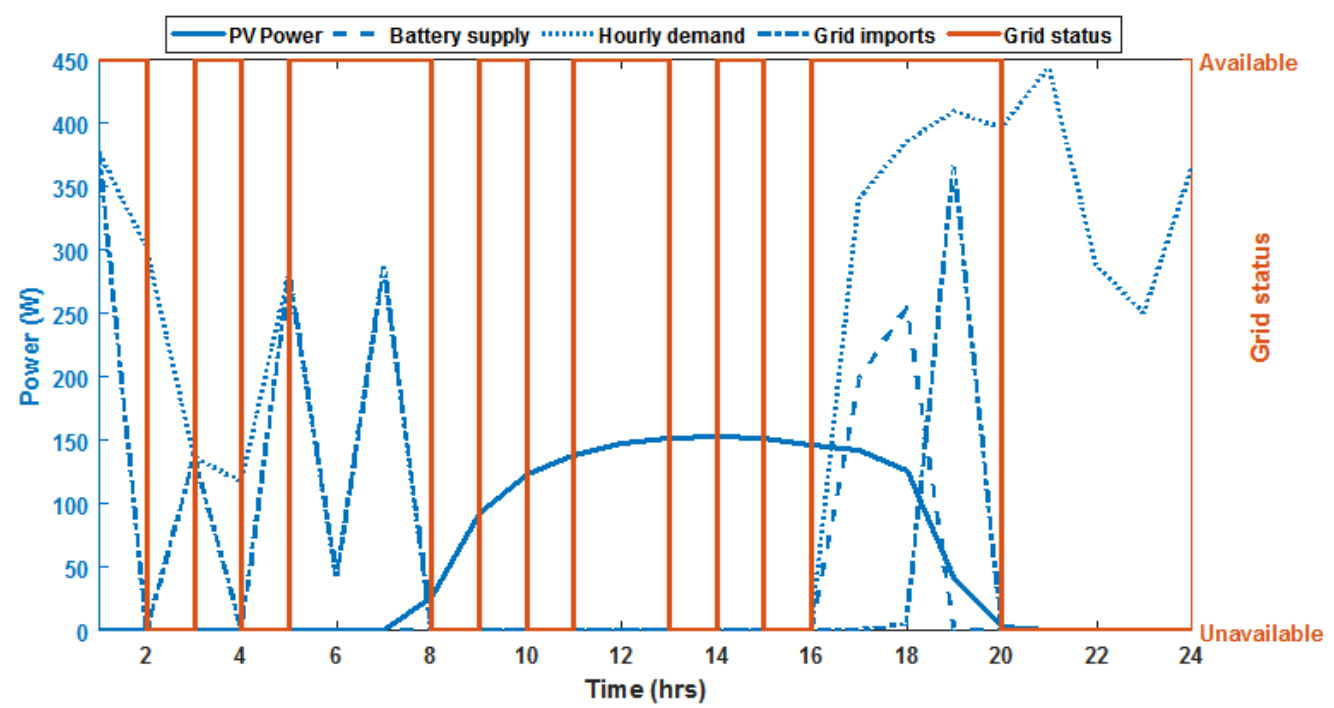

Figure 14: Hourly demand/dispatch profile, utility status and PV/battery capacity

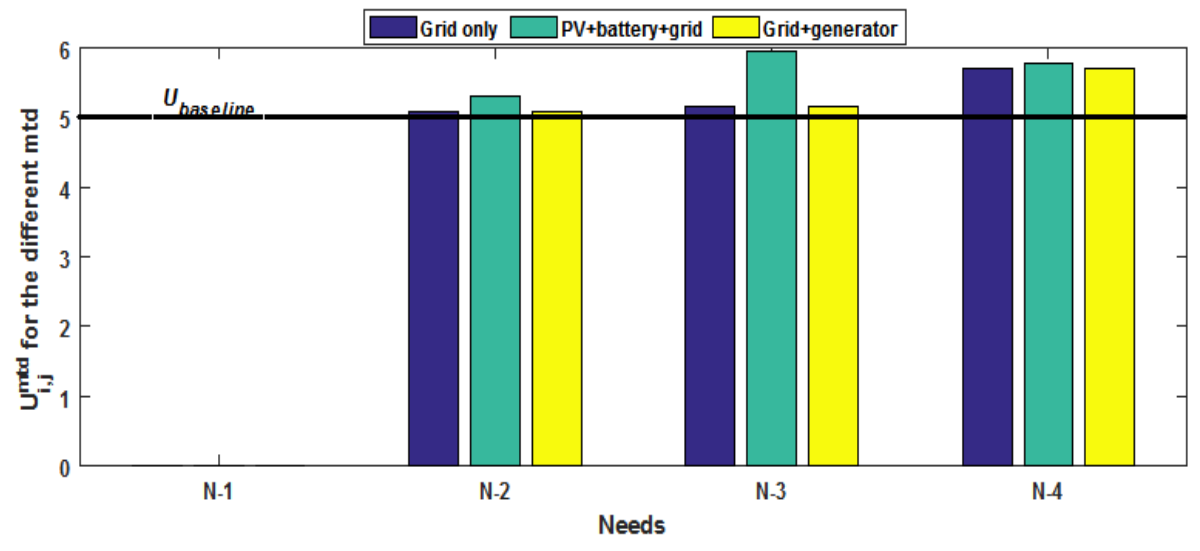

Figure 15: $U_{i, j}^{m t d}$ chart for $4 \mathbf{p m}-\mathbf{5 p m}$ 


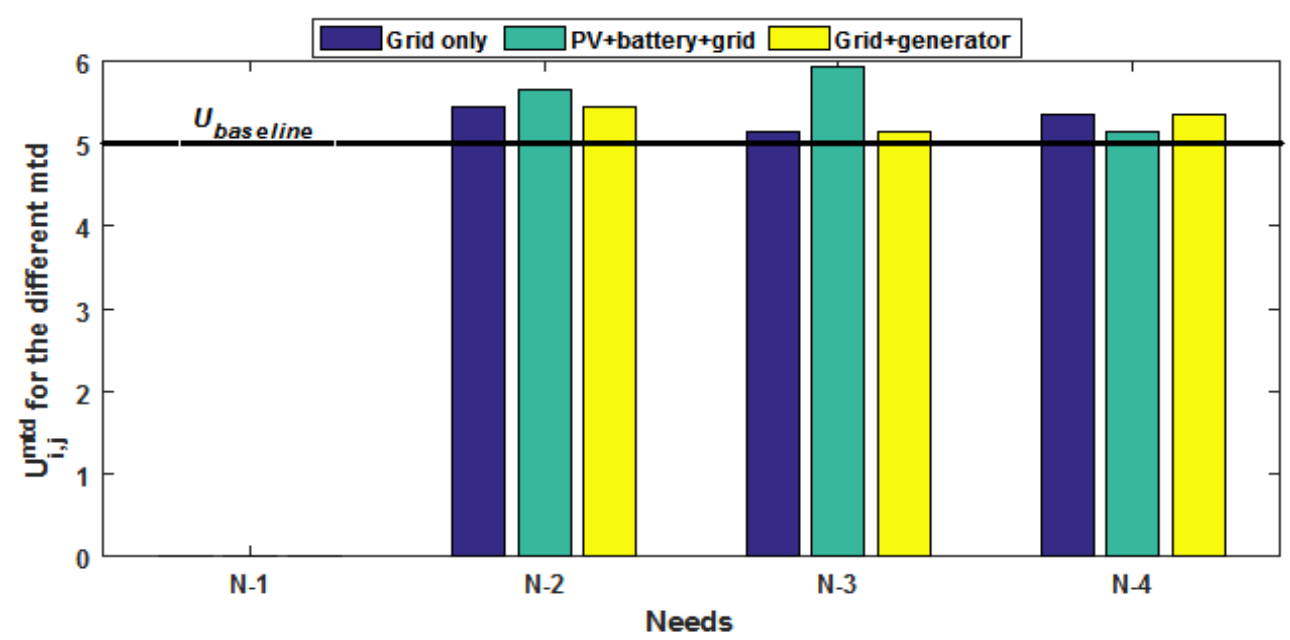

Figure 16: $U_{i, j}^{m t d}$ chart for $5 \mathrm{pm}-6 \mathrm{pm}$

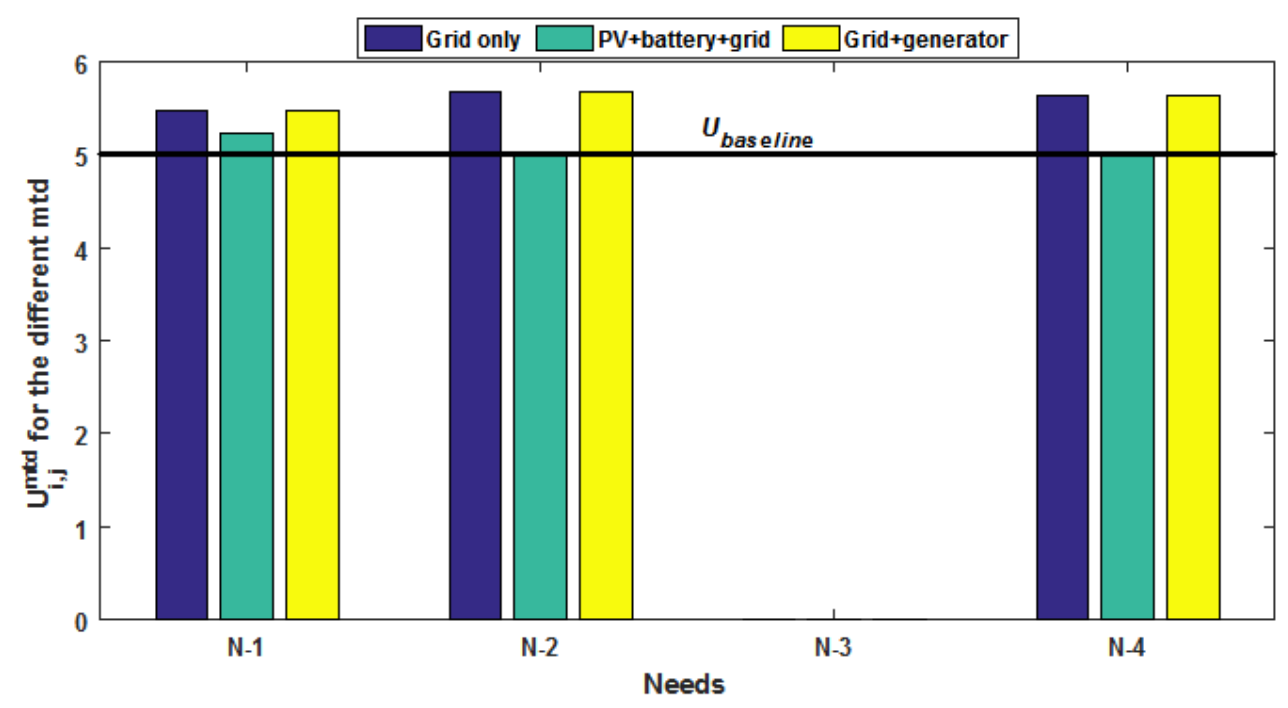

Figure 17: $U_{i, j}^{m t d}$ chart for $6 \mathbf{p m}-7 \mathbf{p m}$ 


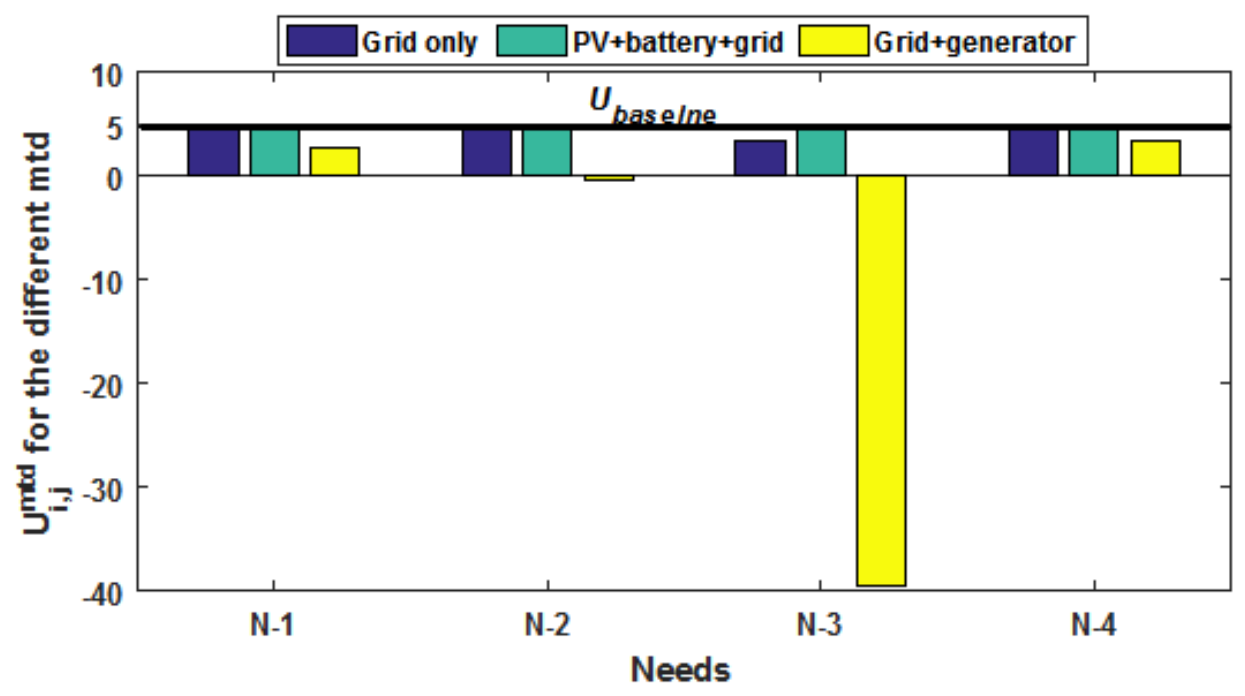

Figure 18: $U_{i, j}^{m t d}$ chart for $7 \mathbf{p m}-8 \mathbf{p m}$

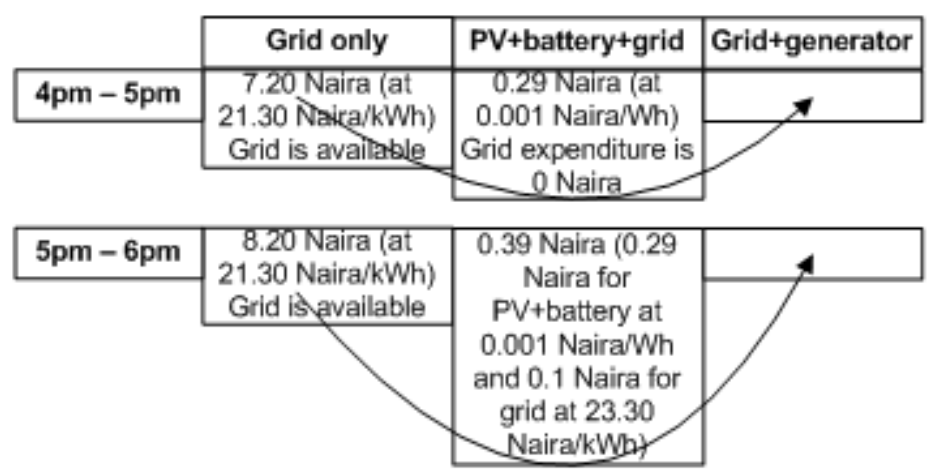

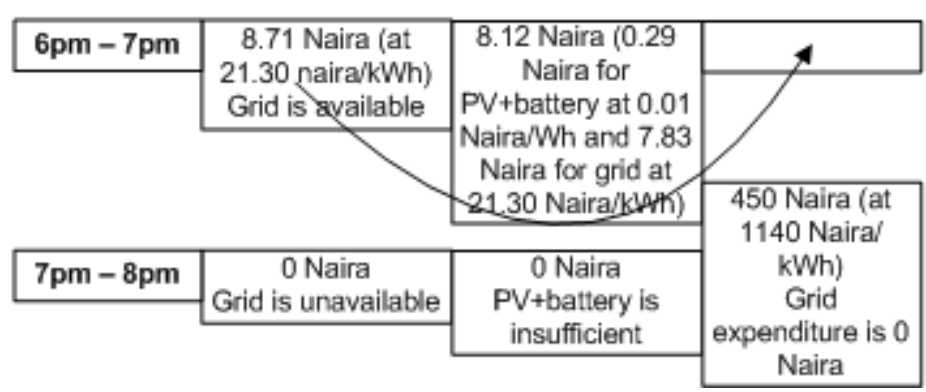

Figure 19: Price fluctuation across the various $\mathrm{mtd}$ 